Discussion Paper No. 01-47

\title{
The Gender Gap in Labor Market Participation and Employment:
} A Cohort Analysis for West Germany

Bernd Fitzenberger, Reinhold Schnabel and Gaby Wunderlich

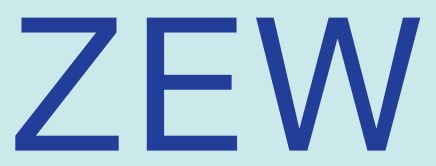

Zentrum für Europäische Wirtschaftsforschung GmbH

Centre for European Economic Research 

Discussion Paper No. 01-47

\title{
The Gender Gap in Labor Market Participation and Employment: A Cohort Analysis for West Germany
}

\author{
Bernd Fitzenberger, Reinhold Schnabel and \\ Gaby Wunderlich
}

Download this and other ZEW Discussion Papers from our ftp server:

ftp://ftp.zew.de/pub/zew-docs/dp/dp0147.pdf

Die Discussion Papers dienen einer möglichst schnellen Verbreitung von neueren Forschungsarbeiten des ZEW. Die Beiträge liegen in alleiniger Verantwortung der Autoren und stellen nicht notwendigerweise die Meinung des ZEW dar.

Discussion Papers are intended to make results of ZEW research promptly available to other economists in order to encourage discussion and suggestions for revisions. The authors are solely responsible for the contents which do not necessarily represent the opinion of the ZEW. 



\section{Non-technical Summary}

Labor force attachment of males and females developed very differently over the last decades. While participation and employment rates of males declined, the opposite happened for females. Thus, the overall employment gap has decreased considerably. However, this process was not uniform for all skill groups and ages as can be shown in this empirical study. We use data on employment and participation over the period from 1975 to 1995 and disaggregate by skill, age and cohort. This reveals gender specific patterns that give rise to interesting economic interpretations.

Employment and participation rates of males have declined over the sample period in all skill groups and in all ages. While the decline is significant at all ages it is impressive at lower and higher ages (25-29 and 55-59). The most pronounced decline can be observed among the low skilled. This drop contrasts to the strong decline in labor supply, measured as the relative size of the group of low skilled. This finding indicates a massive adverse shift in demand for low skilled labor. Among the medium skilled females, employment and participation rose considerably during the 20 years under study. A slight increase can also be found for the low skilled females, which indicates that demand shifts operated more in favor of women. As a consequence, the gender gap in employment has become much narrower, although it still half way from being closed. Still the difference in employment rates of males and females ranges from 5 percentage points (young high skilled) to 30 percentage points (middle aged low skilled). To a substantial degree the narrowing of the gender employment gap is due to a decline in male participation and employment.

By modelling age, cohort and time trend effects for each skill/gender group it is shown that the changes in employment and participation can be explained in the following way. First, employment and participation rates have developed similarly. Second, genderspecific employment (and participation) changes can be separated in three separate additive effects: a time trend that affects all ages and cohorts in the same manner; a life-cycle profile that did not change across cohorts; and, a cohort effect that operates as a pure level effect without changing the shape of the life-cycle profiles. The pure time trends are decreasing for males (particularly so for the low skilled) and increasing for females (except for high-skilled females who display no significant trend at all). This means that the increasing employment of females is not restricted to particular cohorts. Thus, employment has shifted upwards over the 20 sample years for all cohorts. However, for high skilled females we find a cohort effect such that the cohorts who entered the labor market after 1975 have a higher level of employment than the older cohorts. In the group of low skilled females the cohort effects is such that the younger generations display a lower level of employment than the older generations. For males, cohort effects are insignificant.

The convergence of gender-specific employment and participation rates is mainly due to economy-wide trends that affect all cohorts. Our results also imply that the lifecycle behavior of men and women did not change. The pure age (or life-cycle) profiles of male employment and participation are hump-shaped - rising at the beginning and declining at the end of the labor life-cycle. The highest male employment rates are 
reached around age 45 with the flattest profile in the group of the high skilled. The lifecycle patterns of female employment are very different from the male patterns. Female employment still reaches its absolute maximum early in the life-cycle. The life-cycle patterns differ considerably between skill groups. Employment of low-skilled women stays pretty constant (however at a low level) between age 25 and 40 and strongly declines afterwards. In contrast to this, high-skilled women display a very clear Mshape pattern of employment with a peak at age 25, a peak at age 50 and a low at age 35, when employment is 8 percentage points below the life-cycle maximum. Even the minima of female high-skilled employment are still considerably above the maxima of other female employment. The M-shaped pattern of employment of medium skilled women is less pronounced. A large fraction of this group withdraws from the labor market between age 25 and 35 and only a few return around age 45 . The rise in female employment of medium skilled that took place from 1975 to 1995 is due to the increased employment across all ages and cohorts. Taken together we find that the strong trend towards rising employment and labor force participation of women - while increasing overall participation of women - did not change their life-cycle pattern. The traditional gender specific differences in life-cycle labor force (or child-rearing) behavior still seem to be in place. 


\title{
The Gender Gap in Labor Market Participation and Employment: A Cohort Analysis for West Germany ${ }^{1}$
}

\author{
Bernd Fitzenberger, ${ }^{2}$ University of Mannheim, ZEW, and IFS \\ Reinhold Schnabel, ${ }^{3}$ University of Essen
}

Gaby Wunderlich, ${ }^{4}$ ZEW Mannheim

July 2001

\begin{abstract}
Labor market participation rates of West German females have risen during the last decades, whereas participation rates of males have declined or remained stable. Nevertheless, differences in aggregate gender specific participation rates remain. The purpose of this paper is to compare life cycle participation and employment profiles of West German males and females of different skill levels. Going beyond the descriptive cross tabulations of participation and employment rates by year, skill level, and sex, this paper uses a model which simultaneously takes into account the effects of time, age, and birth cohort membership. The estimation results allow for the construction and comparison of gender and skill specific life cycle participation and employment profiles. Even though the gap in average participation and employment rates has narrowed over time, the results confirm a persistent gender gap in the pattern of labor market participation and employment over the life cycle.
\end{abstract}

Keywords: Gender Gap in Employment and Participation, Cohort Analysis

JEL Classification: J16, J2, J71

\footnotetext{
${ }^{1}$ This paper is part of the research project "Holen die Frauen auf? Ein Vergleich von Erwerbsverhalten, Beschäftigung und Verdiensten deutscher und britischer Frauen im Zeitverlauf" at the Centre for European Economic Research (ZEW).

${ }^{2}$ Prof. Bernd Fitzenberger, Ph.D., University of Mannheim, Department of Economics, 68131 Mannheim. E-mail: bernd.fitzenberger@vwl.uni-mannheim.de.

${ }^{3}$ Prof. Dr. Reinhold Schnabel, University of Essen, Department of Economics, 45141 Essen. Email: reinhold.schnabel@uni-essen.de

${ }^{4}$ Gaby Wunderlich, Centre for European Economic Research (ZEW), Department of Labour Economics, Human Resources, and Social Policy, 68161 Mannheim, L7,1. E-mail: wunderlich@zew.de.
} 


\section{Contents}

1 Introduction 1

2 Data Description and Basic Trends 5

$\begin{array}{lll}3 & \text { Empirical Model } & 7\end{array}$

4 Discussion of Results and Graphical Illustrations $\quad 10$

4.1 Participation Rates . . . . . . . . . . . . . . . . . . . . . . . . 10

4.2 Employment Rates . . . . . . . . . . . . . . . . . . . 13

5 Conclusions $\quad 14$

6 References 16

$\begin{array}{lr}\text { A Appendix } & 18\end{array}$

A.1 Data . . . . . . . . . . . . . . . . . . 18

A.2 Methodological Details of the Empirical Approach _ . . . . . . . . . 19

A.2.1 Characterizing Profiles in Participation or Employment Rates . 19

A.2.2 Testing for Uniform Changes over Time . . . . . . . . . . . . 20

A.2.3 Implementation of the Tests . . . . . . . . . . . . . . . 21

A.2.4 Block Bootstrap Procedure for Inference . . . . . . . . . . . 22

A.3 Figures and Tables . . . . . . . . . . . . . . . . . . . . . . 23 


\section{Introduction}

During the last decades female labor force participation rates have risen constantly in all western countries, whereas male rates remained stable or declined. As a result, the overall gender gap in labor market activity rates has diminished (OECD 1997). In Germany (East and West) participation rates and employment rates used to be high compared to OECD-averages (Kommission für Zukunftsfragen 1996: 35). However, economic, political, and sociodemographic change has led to considerable variation in these rates.

The overall participation (employment) rate in West Germany rose from the year 1950 until 1960 from 63 (43) per cent to 70 (47) per cent and fell again until 1984 to 62 (42) per cent. ${ }^{1}$ Because of German unification and its influence on labor demand, the participation rate (employment rate) rose to a bit more than 65 (45) per cent in the beginning of the 90s and fell again to the level of 1984 in the year 1995. The employment and participation rates of the young (15-25 years) and the old (over 60 years) fell considerably because of expanded schooling and early retirement (see BörschSupan and Schnabel, 1998). The rising total participation rate is completely due to a rising female labor market participation (Kommission für Zukunftsfragen, 1996: 37), especially within the core age group (30-45), which overcompensated the decreasing male labor force participation. From 1960 to 1994 the overall employment rate of men fell from 95 per cent to 77 percent. During this period the respective share of fulland part-time employed females rose from 48 to 59 per cent. Thus, the employment gap (without a distinction beween part-time and full-time employment) has decreased from 45 to less than 20 percentage points from 1960 to 1994 in West Germany.

What caused these trends? Large changes in labor demand and labor supply took place over the period in question (see, for example, Franz 1999, Goldin 1990, and Jacobsen 1998). On the demand side we have witnessed changes in demands for goods and services, in the productivity of different groups of workers, in prices for non-labor inputs and the technology of the production processes, and in the competitiveness of the economy. Frequently cited factors for changes in labor demand for women are a general rise in labor demand, which was impossible to satisfy only by employing male workers; the shift in demand for the goods produced in particular sectors, and the lower wages of women compared to men. Males were hit disproportionately by declining labor demand. This was caused by the weakening of job demand in traditional male sectors like manufacturing but may have also been affected by the substitution of female for male workers due to gender specific wage differentials.

On the supply-side changes in household budget constraints and preference shifts took place. As far as females are concerned, their labor supply might have reacted to time saving technologies of household production, changes in family composition (due to increased possibilities of birth control), and skill upgrading. The rising wages of males, and in particular of males at higher ages, through their effects on lifetime potential income and increasing nonearned incomes have presumably lowered their labor supply. As already mentioned, educational attainment has risen for males and females, and a longer duration of schooling has shifted labor market entry to a higher age. Jacobsen's

\footnotetext{
${ }^{1}$ Proportions of resident population.
} 
(1998: 136) conclusion for the US is more or less applicable to all western societies: ${ }^{2}$ "Women have, in general, increased their labor force participation, while men have reduced theirs. Both demand and supply curve shifts have led to these changes. In particular, the increase in available income during the late middle age has led men to retire earlier, and the increased demand for clerical and service labor has led to an increase in women's working, even during child raising years. Female and male work patterns over the life span have become more similar as well." Despite this view, international comparisons of employment patterns uncover some interesting differences which can not be explained using a purely demand-supply perspective, suggesting that social norms in general and institutional frameworks in particular play a decisive role for female employment. ${ }^{3}$

It is conventional wisdom that mothers, and especially mothers of small children, have expanded their labor market participation disproportionately in Germany and other parts of the world. ${ }^{4}$ Mothers of small children are very much dependent on social institutions and norms (Rubery et al. 1999: 87). Across countries one can observe quite different age related participation rates which have to be attributed to international differences in social institutions, such as availability of child care facilities or an employment guarantee during maternity/family leave.

International differences in fertility may be related to those institutional differences, causing differences in female participation as well. In general, one can observe three different age specific employment patterns (see OECD 1988: 49, 134; Rubery et al. 1999: 84) which seem to be due to institutional differences.

- Plateau or inverted U-shaped curve: This is mainly the male employment pattern. Participation rates rise strongly up to an age of around 30 years, stay constant, and start falling strongly at around 55 years. For females this represents an institutional setup under which child raising and employment are compatible (part-time or full-time).

- M-shaped curve or women returner curve: This curve exhibits a valley during the child bearing/raising ages of females. "Such a profile is usually generated when the presence of young children is the major barrier to participation" (OECD 1988: 49). After an interruption due to the family phase, women return to the labor force.

- Left hand peak curve or permanent labor market exit curve: The age related participation rate of females peaks early, at around 25 years, and declines then continuously. "This pattern is observed in societies where many women perma-

\footnotetext{
${ }^{2}$ For Europe see OECD (1988, 1997), Blossfeld/Hakim (1997), Rubery et al. (1999).

${ }^{3}$ See Antecol (2000) for some evidence concerning the influence of social norms on female participation. See Dingeldey (2000) for an European comparison of tax systems and household employment patterns.

${ }^{4}$ The increase in female participation rates can be attributed mainly to part-time work in most European Countries and the US. Furthermore, only the US has had a steady growth in female employment since the beginning of the century. European countries experienced increases in female (part-time) participation beginning with the 70s (see various chapters in Blossfeld/Hakim 1997, for the US see Goldin 1990, Jacobsen 1998).
} 
nently withdraw from the labor force after marriage and/or children" (OECD 1988: 49).

These patterns are not constant over time (see OECD 1988: pp.132, for the change of age related participation rates of women in various OECD countries). Concerning cross sections, it is necessary to differentiate between shifts and changes of their shape over time. Vertical parallel shifts of the age related cross section profile indicate intra cohort participation change over time whereas a change of shape of the cross section profile exhibits inter cohort differences of participation in that successive cohorts move through their employment life cycle and change aggregated age related participation rates. (For each younger cohort of women participation per se as well as timing and duration of job interruptions may have changed gradually.) If cohorts do not behave differently, which one might assume to be the case for men (except for the very young and the old), then aggregate age related patterns in participation rates are the same across cross sections. By looking at differences in participation rates of synthetic cohorts, these processes can be analyzed (see for example OECD 1988: chapter 1 and 5, Shaw 1994: 351, Jacobsen 1998: 114). ${ }^{5}$

Empirical investigation of labor market participation, i.e. labor supply and female labor supply in particular, is usually carried out using structural models and individual data (see Blundell/MaCurdy, 1999, for a comprehensive overview). The aim of this kind of analysis is to understand how individual behavior depends on individual and household characteristics, as well as on macro controls (to allow for demand side effects). In comparison to the wide variety and large number of studies in this field, nowadays, one finds less empirical studies which investigate aggregate labor market participation. ${ }^{6}$ In most cases only bivariate correlations are analyzed, for example, participation trends by education or participation by birth cohort (OECD 1988, 1997, Blundell/MaCurdy 1999, Jacobsen 1998, Kommission für Zukunftsfragen 1996). Our empirical strategy is to investigate the change of participation measures over time, age, and cohort membership simultaneously and to separate as much as possible the effects of these variables.

If participation is affected by shifts in labor demand, by independent shifts in cohort behavior, and, at the same time, by life cycle effects, it is not sufficient to investigate bivariate correlations. The focus of our analysis is, therefore, the change of participation and employment rates across cohorts for men and women of different skill levels between 1975 and 1995 in West Germany, controlling for time and age effects. Disaggregation by skill levels is a way to allow for heterogeneous labor. In this context, we investigate whether the hypothesis of a closing gender gap in labor market activity is true for West Germany. We use an empirical model which allows for age, cohort, and time effects operating simultaneously. If the gender gap in participation (or employment) has declined, we could expect to find cohort effects due to a change in market relevant characteristics, after controlling for time trends, cyclical influences, and aging.

\footnotetext{
${ }^{5}$ The approach of synthetic cohorts in aggregate data examines labor force behavior of demographic groups as they age. The differentiation of cohorts matters a lot, especially for married women: “... cohorts acquire varying amounts of education, have different numbers of children, accumulate different types of labor market experience, and mature in different social climates" (Goldin 1990: 138).

${ }^{6}$ Examples of this kind of analysis for the U.S. are Goldin (1990), Killingsworth/Heckman (1986), and Pencavel (1986).
} 
Labor force participation rates for men and women rise with increasing educational attainment (see OECD, 1997, for a descriptive international comparison of participation rates of men and women by skill level). For women however, the impact of education on participation is even stronger. "Although a gender gap in labor force participation remains among those with the highest levels of educational attainment, the gap is much narrower than among those with lower levels of educational attainment. In general, with each additional attainment level the difference between the participation of men and that of women decreases by 10 percentage points: from about 30 percentage points at less than upper secondary and 20 at upper secondary to 10 at tertiary level (...) Since earnings tend to increase with educational attainment, incentives are greater for persons with a better educational background" (OECD 1997: p.243).

This is reflected in various forms in our subsequent empirical analysis. First, differences in participation across education groups should be visible in the estimated intercept and time trends. Second, economic restructuring, obsolescence of unskilled work, as well as rising educational attainment, i.e. smaller aggregates of the unskilled in comparison to larger aggregates of medium and high skilled, should result in different time trends across skill levels. ${ }^{7}$ Low skilled male employees should exhibit a negative time trend, whereas for high skilled employees we expect the time trend to be positive, which we would take as evidence for a fall in labor demand for low skilled and a rise in demand for high skilled employees. For females, we expect the time trends to be positive across all skill levels, because, if substitution of female for male unskilled work took place due the aforementioned gender wage gap, then the demand for low skilled women should have risen as well. A related argument which could support this hypothesis is that the effective labor supply of low skilled women is comparatively low (see above), i.e. low skilled women are both cheap and scarce compared to men. In addition, we expect to find different profiles of participation for men and women across age, because age related participation of females is still very much influenced by the birth of children.

Germany is considered as a "conservative welfare state" (Esping-Andersen 1993, Dingeldey 2000) which exhibits disincentives for mothers to work by means of tax splitting among spouses, survivor pensions, few child care facilities for children under age three, nursery schools with short opening hours, schools with irregular hours (usually without classes in the afternoon), and a guarantee of long (paid and unpaid) family leave. As a result, the male breadwinner model is still prominent among married couples with young children (Blossfeld/Rohwer 1997: 170). ${ }^{8}$ Additionally, this implies that, due to educational upgrading and a growing labor market attachment of women changing the labor market relevant characteristics of successive cohorts, we expect cohort effects to be at work. Cohort effects would also include, for example, declining fertility and the erosion of restrictive social norms with respect to the acceptance of working mothers. Because we do not make a distinction between part-time and full-time participation and employment rates, the female left hand peaked age related pure cross section profile should have changed to a more M-shaped profile (see OECD 1988: 132) because

\footnotetext{
${ }^{7}$ This argument refers to "skill biased technological change", see Blau/Kahn (1997) and Berman/Bound/Machin (1998).

${ }^{8}$ Among others (e.g. Hakim 1993), Blossfeld/Rohwer (1997) claim that the impressive increase in women's labor force participation is due to a enormous rise in part-time employment. See also Dingeldey (2000). Comparing 10 European countries she states that the incentives to maintain the male breadwinner model are very strong in West Germany.
} 
of cohort effects in the case of West Germany. Cohort effects should be weaker for high skilled females, because their labor market participation rates already used to be relatively high in the seventies. For males, the traditional inverted U-profile should have changed little, except for earlier retirement and longer schooling. This change is rather unlikely to become visible as significant cohort effects in our data because we restrict our sample to the age group between 25 and 55 years.

The remainder of the paper is organized as follows. Section 2 describes the data and discusses some basic trends. Section 3 develops the empirical model to distinguish cohort, age, and time effects. The empirical results are presented and discussed in section 4 . Section 5 concludes. The appendix provides more details on the data and the empirical model as well as tables and figures.

\section{Data Description and Basic Trends}

Since 1957, the Federal Statistical Office has conducted an annual population survey called the Micro-Census (Mikrozensus), which can be compared to the U.S. Current Population Survey (CPS). The Micro-Censuses are the main source of official population and labor market statistics in Germany. The surveys are one percent random samples of the residential population in Germany, stratified by some regional variables (state, size of city or county, etc.). Contrary to the CPS, the interviews are all conducted at the same time of the year so that no seasonal information is available. After the reunification of Germany, the East German population has been added. The primary sampling units are households. All household members age 16 and older are personally interviewed. Before German unification, the sample size was approximately 250,000 households and 600,000 persons. The questionnaire is regulated by federal law and includes information on demographics, household structure, labor market status, and sources of income. Unfortunately, access to the raw data is limited because of restrictive data protection regulations. Upon submission of a research proposal to the Federal Statistical Office, the latest surveys can be obtained for scientific use. The older waves are still not available to the scientific community.

However, we could use the subsamples of the Micro-Census at the ZUMA Mannheim which contain a limited - and for our purpose sufficient - collection of variables for several survey years $(1976,1980,1982,1985,1987,1989,1991,1993,1995)$. The subsamples range from $70 \%$ to $98 \%$ of the original samples. ${ }^{9}$ We had to restrict the sample period due to a lack of consistent information on the skill level in the older censuses. Our working samples cover all West German residents in private homes (excluding institutionalized population). This also includes all nationalities living in Germany. For obvious reasons, we have to exclude the East German population from our analysis.

The employment status variable in the Micro-Census is defined according to the ILOStandard. A worker is considered unemployed ("erwerbslos") if he or she did not work and was actively searching for a job. Similarly, a person is considered employed

\footnotetext{
${ }^{9}$ The subsamples are: 1976, 1980, 1982, 1985, 98\%, 1987, 1989, 1991, 1993, $199570 \%$.
} 
("erwerbstätig") if he or she worked for money (either self- or dependently employed), and out-of-labor force ("nicht erwerbstätig") if neither of the former two conditions applied. Adding up the cases in the three categories yields the population.

The definition and measurement of labor market statuses in the Micro-Census differ from those that are used by the Federal Labor Office (Bundesanstalt für Arbeit). The labor market status variables in the Micro-Census are self-reported. The official rate of unemployment ("arbeitslos") is based on the entire population of persons who are officially registered as unemployed. The official unemployment rate is then calculated as the number of registered unemployed divided by the number of dependently employed (only civilian). The unemployment rates that we report are in general lower than the official rates due to (i) underreporting of unemployment in the survey, (ii) the ILO-requirement of active job search, and (iii) inclusion of the self-employed in the denominator.

Our analysis considers employment rates and participation rates. The employment rate (ER) is measured as the number of employed persons divided by the number of persons in a given age group for each year. The participation rate $(\mathrm{PR})$ is calculated as the number of labor market participants (i.e. employed plus unemployed) divided by the total number of persons in a given age group for each year. We disaggregate further by gender and skill level.

We distinguish three skill levels:

low skill $(\mathrm{U})$ : $\quad$ no high school degree and no vocational training medium skill (M): high school degree or vocational training, less than college degree

high skill (H): college degree (either "Fachhochschule" or "Universität")

Item non response in the skill variable may have two reasons. First, many persons have not yet finished their education. This is why non response is decreasing with age. Second, in some years the answer to this question has been voluntary and some persons refused to answer. For those years, we corrected the employment and participation rates using also information from the years when the question was compulsory (see appendix A for a description of the method of imputation).

The sample sizes are large. The average size of the age-skill-gender cells is more than 3000 in each year and never falls below 2000. The employment and participation rates can thus be estimated very precisely.

Figure 1 in the appendix A.3 is separated into females and males and displays how the three skill groups developed separately over time based on the raw data. We plot the relative size of a skill group (relative to the number of persons in the age group at time t) against time. The skills of the female labor force have increased dramatically over the 15 sample years. In 1976 over 50 percent of the women aged 40 and above did not have any formal training and only less than 5 percent of these age groups had a college degree. In the year 1995 the same age groups display much higher skill levels. The fraction of low skilled males halved over the sample period 1976 to 1995 for age groups above 30. However, due to the increasing duration of education, the relative number of low skilled has stayed constant for younger males (age group 25-29). In total, the 
labor supply of low skilled has dropped considerably. However, there is still a gender skill gap: in the year 1995 more than 20 percent of women report no formal training at all, while the numbers for men are much lower at 10 to 15 percent.

The relative size of the medium skilled male groups did not change at all, whereas the numbers of medium skilled women have increased and now almost reach the male level of about 70 percent. The relative size of the high skilled more than doubled during the sample period. Women, especially, increased their college participation. While 17 percent of males in the age group 30-34 had a college degree in 1995, only 12.5 percent of women reported a college degree. Again, since German students usually finish their college degree between the age of 25 and 30, the age group 25 does not display any significant change. In total, the labor supply of high skilled men and women has increased dramatically over the past 25 years.

The charts in figure 2 in the appendix A.3 show the trends in labor force participation based on the raw data for the age groups 25-29 (age 25), 35-39 (age 35), 45-49 (age 45), and 55-59 (age 55). (The shapes of the participation rates are very similar and are not shown here.) The employment trends differ greatly between males and females. The age-specific employment rates have declined across all skill groups for males. This is not the case for women: female age-specific employment rates have either risen (in the group of the medium skilled) or have stayed fairly constant (in the groups of the low skilled and the high skilled).

A very outstanding feature is the massive decline in the employment rates of low skilled males. At younger and older ages, employment rates were lower than 55 percent in the year 1995. Only about half the working capacities of these groups are used. For the middle age groups of the low skilled males, the decline was still considerable (from above 90 percent down to barely 80 percent) but not as steep. The employment rates of women in the group of the low skilled have no clear trend. Employment has increased slightly in the middle age groups.

The gender gaps in employment rates have narrowed considerably over the 20 sample years in the groups of low and medium skilled workers. The gender gap used to be around 40 percentage points in 1976 for the low and medium skilled but, depending on which skill group and age is studied, it has narrowed to between 13 and 25 percentage points in the mid 90's.

In the group of the high skilled the gender gap has not changed much. It hovers around 10 percentage points in the younger age group, and it has narrowed some 5 to 10 percentage points to around 18 percent in the higher age groups.

\section{Empirical Model}

We investigate the labor force participation rates (PR) and employment rates (ER) over the years 1976 to 1995 for different cohorts stratified by gender and skill levels. A cohort is defined by the year of birth. We use the framework that was first developed in MaCurdy and Mroz (1995) to analyze wage trends in the United States. It has 
also been applied in Fitzenberger (1999), Fitzenberger and Wunderlich (2000), and Fitzenberger, Hujer, MaCurdy, and Schnabel (2001) in the context of estimating wage equations. This section outlines the basic empirical approach. Further methodological details can be found in the appendix.

Based on longitudinal data, we would like to separate the patterns of employment and participation in age, cohort, and time effects. The age effect describes how the labor market behavior of a given cohort changes as the cohort ages. The time effect describes how macro economic shocks shift the labor market outcomes for a given cohort. Cohort effects summarize the difference between cohorts. Of course, it is well known that the three effects cannot be separately identified. More specifically, the linear effects of time, cohort, and age are not separately identified without further prior assumptions. This is due to the fundamental identity that links birth year c, age a, and calendar time $t$

$$
t=c+\alpha .
$$

Let PER denote the variable PR or ER in the following. PER for a cohort $c$ at age $\alpha$ is represented as

$$
\operatorname{PER}(c, \alpha)=g(t, \alpha)+u
$$

where $\mathrm{u}$ is a residual component. ${ }^{10}$ PER can alternatively be represented as a function of $\alpha$ and $t$ (or even as a function of $c$ and $t$ ):

$$
g(c, \alpha) \equiv g(t-\alpha, \alpha) \equiv f(t, \alpha)
$$

$g(c, \alpha)$ specifies the longitudinal (cohort) profile for a given cohort $c$ over age. $f(t, \alpha)$ specifies the cross-sectional age profile at a given $t$. Our empirical analysis uses a polynomial representation for $g(c, \alpha)$, which is additively separable in cohort, time, and age effects

$$
g(c, \alpha)=G+K(c)+A(\alpha)+B(c+\alpha)
$$

where $A(a)$ and $B(c+\alpha) \equiv B(t)$ are polynomials in $\alpha$ and t respectively. Note that in contrast to the linear effects, coefficients on the second, third, etc., powers in $c$, $\alpha$, and $t$, are identified. The specification of the cohort effect $K(c)$ differs between those cohorts born before 1951 (i.e. younger than 25 in the first sample year 1976) and younger cohorts born after 1951 .

$$
K(c)=K_{b 2} \cdot c b^{2}+K_{b 3} \cdot c b^{3}+K_{a 2} \cdot c a^{2}
$$

\footnotetext{
${ }^{10}$ We have also experimented with a logistic transformation in PER. The specification applied here uses the level of PER as the left-hand-side variable in the regression, i.e. a linear probability model based on grouped data.
} 
where $c a=0$ and $c b=c$ are for cohorts born before 1951 as well as $c a=c$ and $c b=0$ for cohorts born after 1951. We make this distinction since we do not observe labor market entry for older cohorts. The choice of polynomials is justified since the analysis does not intend to forecast PER outside of the observed sample. In the empirical analysis we actually center the variable $\alpha$ around age 25 and the variable t around year 1976. Thus, cohort $c=0$ is the cohort born in the year 1951 .

Equation (4) allows for linear terms in $\alpha$ and $t$ but not in $c$. It is clear that, formally, the linear terms are not identified, i.e. the coefficient on $\alpha$ estimates $(A 1-K 1)$ and the coefficient on $t$ identifies $(B 1+K 1)$, where $A 1, B 1$, and $K 1$ are the unknown coefficients of the linear terms in $\alpha, t$, and $c$, respectively. As an identifying assumption, the linear cohort effect $K 1$ is set to zero. This assumption is motivated by equation (4) - see also equation (11) in the appendix - which for a given cohort allows a separation of changes over time into a pure age and a pure time effect; both are common to all cohorts in the labor market. In light of this condition, setting the linear cohort term to zero is quite natural based on the following argument. If $K(c)=0$, i.e. only a linear cohort term exists, then the entire cross-section profile $f(\alpha, t)$ exhibits purely parallel shifts over time, a situation, one would not naturally characterize by "cohort effects".

Note that the sum of two effects can be identified without additional assumptions. For instance, the sum of age and time effects is identified and yields the longitudinal profile (cohort profile) $A(\alpha)+B(t)$ for each cohort as the change over time and age relative to the cohort specific level $K(c)$. The shape of these longitudinal profiles differs between cohorts since each cohort experiences the time (macroeconomic) effect at a different point of the life-cycle.

An important issue is that of separability of the three effects as assumed in equation (4). It is not clear from the outset that the labor market outcomes can be represented by such an additive function. We denote this restriction as the hypothesis of a uniform insider trend $\mathbf{H}_{\mathbf{U I}}$ since specification (4) implies that the cohort profiles depend only upon age and time, relative to the cohort specific $K(c)$, defining the level at the entry into the labor market. This hypothesis can be tested without further identifying restrictions. We use specific interaction terms of $\alpha$ and $c$ for this test (see appendix). In testing the separability restrictions, it may be important to use robust estimators for the variance-covariance matrix of the parameters. To this end, we use a block bootstrap procedure that controls for a fairly general pattern of correlation in the error term (see appendix).

Only if the hypothesis of separability cannot be rejected, is it justified to speak of age, cohort, and time effects as being separate effects - conditional on our identifying assumption for the linear terms. Otherwise, the "age" effects depend also on cohort and calendar year and so on. A stronger restriction on the specification $g(c, \alpha)$ would be $K(c)=0$. We denote this as uniform growth hypothesis $\mathbf{H}_{\mathbf{U}}$ since under this hypothesis no level differences between cohorts exists. This hypothesis is tested separately for the cohorts born before 1951 and those born afterwards.

In the empirical analysis, we also use orthogonalized time dummies in order to model cyclical movements of employment around its trend (see appendix). We start the estimation with the most general formulation of the model, including interaction terms 
of age, time, and cohort. We then search for the most parsimonious specification that is compatible with our data. The empirical estimates and graphical illustrations are presented in the following section.

\section{Discussion of Results and Graphical Illustrations}

Based on the empirical framework introduced in the previous section, this section presents the empirical results. We use a variety of graphical illustrations, which prove convenient to describe the findings of this paper. The detailed estimation results of our final preferred specifications can be found in the appendix (see table 1 and 2 for estimations of participation and employment rates for males and females of the different skill levels). The final specifications are the outcome of testing for uniformity of time trends and age profiles across cohorts. Table 1 and 2 only contain the remaining significant regressors. Significance, respectively joint significance of the coefficients, is given at conventional levels. Standard error estimates are obtained by using a block bootstrap procedure to take into account dependencies of cells across time and cohorts (see appendix for details). Because separability of age and time is not rejected for males and females of all skill groups, it is possible to construct time trends as well as age profiles in all cases.

The main findings of the empirical analysis are as follows: First, the final specifications do not differ between employment and participation rates (implying similarity of both measures, as far as model specification is concerned, even though participation rates take unemployment into account) but between males and females. In the female category they differ across skill groups (see table 1 and 2). For males, the most restrictive model specification 1 is always justified and exhibits a linear time trend and a quadratic age profile. This applies to participation rates, as well as employment rates, and shows that within the observation period employment and participation rates of males change less than those of females. In particular, employment and participation rates of males exhibit no cohort effects, and they do not swing across age groups - in contrast to the case of females involving a significant third order age polynomial and cohort effects for all skill groups. Figures 3 (participation rates) and 5 (employment rates) display to what extent age profiles for various cohorts of males and females differ, i.e. how age profiles change over time, if cohort membership is held constant. These graphs show clearly that males' profiles do not change their shape over time but shift somewhat but that females' profiles change their shape and shift as well. The exception is the case of high skilled females, whose cohort specific age profiles exhibit no differences over time.

\subsection{Participation Rates}

The participation rate in a cohort-year cell is defined as the sum of employed and unemployed among the total number of persons within the cell (see section 2). Table 1 and figure 3 in the appendix contain the empirical results for participation rates. The most important aspect of the results is that male and female participation rates follow different models. In the case of males, the same model specification applies to all skill 
groups, such that a linear time trend and a second order age profile describe the data sufficiently. Descriptive evidence shows that average participation rates are lower for low skilled men compared to men with higher skill levels (see section 3). In addition, the time trend is significantly negative for all skill groups but most negative for the low skilled. The time trend for low skilled workers may mingle a discouraged worker effect, declining demand for low skilled workers (because of skill-biased technological change), or substitution of female for male work. Comparing the age profiles, low skilled men differ again very strongly from medium and high skilled men. Their age profile is very steep, corresponding to their participation starting from a lower level. This finding of a low labor market attachment for low skilled men in their late twenties and early thirties is puzzling at first glance. However, this group includes persons in higher education (university, technical college) who have not finished their degree. In contrast, high skilled men exhibit the flattest age profile, declining only little after the age of 45. This observation reflects high labor market attachment, even at the end of the career. A marginally steeper decline after the age of 45 years can be detected for medium skilled workers. Taken together, male participation rates declined over time, steepest for the unskilled (-7 percentage points) and only little for the other skill groups (-1 percentage points). Age profiles show the traditional male plateau pattern, which is modelled best by a second order age polynomial.

The final specifications for females differ very much from the male specifications, and there are differences across skill levels as well. Descriptive evidence shows that the ranking of participation rates by skill level is even more pronounced than is the case for men. Only for high skilled women is average participation nearly as high as for medium and high skilled men. Concerning the linear time trend, we find a rise in participation for low skilled (13 percentage points) and medium skilled (17 percentage points) women, in contrast to high skilled women, who do not expand their participation over time. An explanation for an increasing labor market attachment at lower skill levels is that demand for female labor, caused by an expanding service sector or by the gender wage gap, has risen. This, along with a changing attitude towards work, might motivate employers to substitute female for male workers. A non-existent time trend for high skilled women might indicate that a further extension of labor supply is impossible for this skill group (higher education might always have been a commitment for a high degree of labor market attachment) or that demand for high skilled females is already saturated. Furthermore, a constant gender wage gap for this group (see Fitzenberger/Wunderlich, 2000) might prevent some high skilled females from participating in the labor market in light of the difficulty to coordinate family and (full time) employment.

A third order age polynomial (which corresponds to our hypothesis stated in the beginning of the paper) fits the data for females best. Very interesting is the fact that the age patterns differ very much across skill levels, see figure 3: Participation rates of low skilled women do not change very much until age 45 and then begin to fall by a total of 16 percentage points until age 55. Medium skilled women reduce their participation rate by 14 per cent between age 25 and 35 . Their participation recovers a little until age 45 but then declines further. The participation rate of medium skilled females declines by 24 percentage points between age 25 and 55 with a comparatively stable period around age 40. Participation of high skilled women falls by 10 percentage points until age 35 , climbs back to its starting point until age 50, and then falls again until age 
55. Compared to men, it seems to be the case that the comparatively few low skilled females who would like to work, do so until they are 45 years old. We have, perhaps, left out important parts of the family phase of the low skilled women by restricting the data to cover only individuals who are at least 25 years old or the family phase is more spread out. Medium and high skilled females' participation rates show clearly the family phase valley, and high skilled females tend to return to the labor market, in contrast to medium skilled females, who rather exhibit a pattern of permanent exit from the labor market. In contrast, the younger cohorts of low skilled females exhibit both an age profile and a cross-section participation pattern almost without a valley (see figure 4). Figure 4 displays differences in age profiles of various birth cohorts caused by the time trend which applies to all cohorts, see below. A possible interpretation of this finding is that low skilled females are split into a group of family orientated females who do not supply any labor and a group of females who would like to work. Maybe the latter can not afford to stay at home very long.

One could suspect, in general, that low skilled low paid females have, if married to a comparatively well payed partner, the strongest incentives, caused by the tax system, to stay out of the labor market. This possible splitting of low skilled females may reflect a selection process caused by tax splitting. In contrast to low skilled females, it might be the case that medium and high skilled females are reconciling family and employment to a much larger extent (maybe through part time employment), in that incentives caused by tax splitting are weaker for these skill groups and these females use their higher human capital more effectively.

The empirical model makes a distinction between cohort effects before and cohort effects after 1976. For the cohort profiles in figure 3, cohort effects for the year 1976 are set to zero. The time axis depicts the labor market entry of the various birth cohorts, which we assume to occur at age 25 . The relevant part of the picture starts in entry year 1950 when the West German economy started recovering from the war. It becomes apparent that successive cohorts of high skilled females have expanded their participation, starting with birth cohort 1925, who entered the labor market in 1950. Medium skilled females expanded their participation rate as well but less so than high skilled females. This is in contrast to low skilled females, whose participation rate fell nearly continuously for all successive cohorts, staying constant for birth cohorts 192550. We do not find cohort effects for birth cohorts of medium and high skilled females entering the labor market after 1975.

The hypothesis that male and female participation patterns have become more similar between 1976 and 1995 is evaluated in figure 4. Figure 4 depicts how the actually experienced profiles differ across cohorts, i.e. how the estimated cohort specific age profiles change over time. We use the cross section profile in the year 1985 as reference. The curve represents the cross-section age profile for all cohorts present in the labor market in the respective year. The other curves represent the age profiles for three birth cohorts. These cohorts are 30, 40, and 50 years old in 1985.

What we can say about increasing similarity of male and female participation patterns is that age related participation rates have increased over time (across cohorts) for low and medium skilled females and decreased for males in general, especially for low skilled males. This means the gender gap in participation rates (without a distinction between 
full and part time employment) has decreased for all skill groups. For females, the participation profile across age still exhibits the family valley. The valley, in general, is very weak for the low skilled but the age related profile of the medium skilled females appears to have changed across cohorts from a permanent labor market exit pattern to a women returner pattern. However, as indicated by the acceptance of the separability hypothesis $H_{U I}$, the age profile, or life cycle profile, is uniform across cohorts. Therefore, the true life-cycle profile of medium skilled women has not (!) changed i.e. the returner pattern in the data is actually a pure time effect which applies to all cohorts.

\subsection{Employment Rates}

The employment rate in a cohort year cell is defined as the share of employed among the total number of persons within the cell. Table 2 and figure 5 in the appendix show that male and female employment rates follow different models, which are very similar to the structure found for participation rates in the previous subsection.

The time trend is again negative for all skill groups and steepest for the low skilled. For them, we detect an even larger negative slope of the time trend as is the case for participation ( 8 percentage points). It amounts to a 16 percentage point employment loss over 20 years. The negative time trends in employment of medium and high skilled males are only a little more pronounced as their negative trends in participation. As stated before, unemployment among the low skilled is high in comparison to more highly skilled men. Our results for the period of observation confirm the conventional wisdom that unemployment among the low skilled is much higher than for more highly skilled men. Because participation rates do not follow such a marked downward trend, this suggests a skill-biased decline of labor demand. Later, we will show that within skill groups a considerable substitution of female for male work did not happen.

Comparing the male age profiles in employment rates, we observe no considerable differences to participation rates. This finding and the non-existence of cohort effects in both cases show that macro economic circumstances are probably most decisive for changes in male employment rates.

The final specifications for female employment rates differ very much from the male specifications and across skill levels. Concerning the time trend, we find a rise of 4 percentage points in employment rates for low skilled women, which is 10 points less than the rise in participation rates. Like males, unemployment among low skilled females increased. Thus, one could suspect that no or little substitution of female for male labor took place. However, this finding could also be attributable to sectoral change. What has to be recorded here is the fact that labor supply of low skilled females has risen but that a considerable amount of it translated into unemployment.

Medium skilled females expand their labor supply the most in comparison to the other skill groups. Interestingly, this labor supply has almost completely met its demand on the market, which can be seen by comparing the time trends in participation and employment rates for medium skilled females in figures 3 and 5. Employment rates of medium skilled females rise by 15 percentage points over time, whereas their participation rates rise by 17 percentage points. This is in stark contrast to both low and high 
skilled females. The latter exhibit neither a rise in participation nor in employment rates, and the former show a large increase in labor supply (see above). Altogether we may suspect that medium skilled - maybe part time employed - females have partly replaced low skilled males. To examine this hypothesis more deeply, a distinction between sectoral employment rates as well as full and part time employment is necessary.

Age patterns of female employment rates differ very much across skill levels (see figure 5). Age profiles of participation and employment differ only marginally for medium and high skilled women. Medium and high skilled females' employment rates mirror clearly the family phase. Whereas high skilled females completely return to employment medium skilled females tend to follow the pattern of permanent exit. In contrast to the other skill groups, the age related employment profile of low skilled women differs from the participation profile. The curve exhibits an early family valley and rises considerably between the ages of 25 and 45 .

Cohort profiles in employment rates are very much similar to cohort profiles in participation rates, with the exception that medium and low skilled women's profiles reverse. Besides, the structure of the cohort effects, i.e. effects before and after 1976, does not change compared to the models for participation rates.

Figure 6 displays differences in life cycle employment profiles of various cohorts in relation to a reference cross section (of all cohorts) in 1985. In comparison to figure 4, it becomes clear that the time trend shifted male employment rates more than male participation rates. Concerning the increasing similarity of male and female employment patterns, employment rates have increased for low and medium skilled females and decreased for males in general, especially for low skilled males; i.e. the gender gap in employment rates has decreased for all skill groups (see figure 6). This is much like the gender gap in participation rates, which shrank as well. Although the case is weak for low skilled females, all female age profiles of employment rates exhibit the family valley, even for the younger cohorts. However, despite the positive trends and the presence of cohort effects, the life-cycle profiles (三 pure age effects) of females with different skill levels have not changed between 1976 and 1995. It is the time trend which causes differences in the location of cohort specific life cycle employment profiles, being visible where the profiles of the various cohorts overlap.

\section{Conclusions}

Based on data from the German Microcensus, we investigate life cycle participation and employment profiles of West German males and females of different skill levels over a time period of 20 years. The empirical model simultaneously takes into account the effects of time, age, and birth cohort membership. Since the hypothesis that age profiles are separable from the time trend is not rejected, it is possible to construct and compare gender and skill specific life cycle participation profiles. Even though the gap in average participation and employment patterns has narrowed over time, the overall results confirm a persistent gender gap in life cycle profiles. The estimated participation and employment patterns are quite similar. Therefore, we will focus here on the differences. 
The male employment pattern, irrespective of skill level, can be characterized as an inverted U-shape. There is no indication that participation and employment patterns of males are affected by labor supply reductions due to the family phase. In contrast, the data for females are best represented by an age profile of third order, consistent with the presumption that life cycle participation and employment profiles of women are still very much influenced by family formation processes; this is still the case for the younger cohorts as well. An exception are low skilled females whose participation and employment rates are much lower in comparison. The remarkably flat and low level profile of low skilled females could indicate that participation incentives are weak for this group. This may partly be due to tax splitting. An additional explanation may be that timing and distribution of the family phase differs across the various skill levels and that by restricting the sample to persons aged 25 to 55 , important parts of the family phase are cut off.

In contrast to males, and with the exception of high skilled females, participation and employment of women increase significantly over time. However, employment rates of low skilled German women have not increased to the same extent as participation rates. In addition to the considerable negative time trend found for low skilled males, this finding supports the hypothesis of a decreasing demand for low skilled individuals.

Although the age profiles within the respective groups are common for all cohorts observed within the time frame, the actual participation and employment rates experienced over the life cycle change across subsequent cohorts. This is due to the time trend but also reflects a change of cohort specific starting points of the actual life cycle profile experienced. We actually do not observe a "permanent exit pattern" for the youngest cohorts of females. This finding can probably be attributed to part-time employment of females after the family phase. Because it is also plausible to assume that returner behavior into full- versus part-time differs across skill levels, further research should distinguish between full- and part-time. 


\section{References}

Antecol, H. (2000) An Examination of Cross-Country Differences in the Gender Gap in Labor Force Participation Rates. Labour Economics, pp.409-426.

Berman, E., J. Bound and S. Machin (1998) Implications of Skill-Biased Technological Change : International Evidence. The Quarterly Journal of Economics, 113, pp.1245-1279.

Blau, F. and Kahn, L. (1997) Swimming Upstream: Trends in the Gender Wage Differential in the 1980s. Journal of Labor Economics, 15, pp.1-42.

Blossfeld, H.-P. and G. Rohwer (1997) Part-Time Work in West Germany. In: Blossfeld, H.-P. and C. Hakim (eds.) Between Equalization and Marginalization. Women Working Part-Time in Europe and the United States of America. Oxford: Oxford University Press, pp.164-190.

Blossfeld, H.-P. and C. Hakim (eds.) (1997) Between Equalization and Marginalization. Women Working Part-Time in Europe and the United States of America. Oxford: Oxford University Press.

Blundell, R. and T. MaCurdy (1999) Labour Supply: A Review of Alternative Approaches. In: O. Ashenfelter (ed.) Handbook of Labor Economics, Volume $3 \mathrm{~A}$.

Börsch-Supan, A. and Schnabel, R. (1998) Social Security and Retirement in Germany. In: J. Gruber und D. Wise (eds.), Social Security and Retirement around the World, Chicago: University of Chicago Press.

Dingeldey, I. (2000) Einkommensteuersysteme und familiale Erwerbsmuster im europäischen Vergleich. In: I. Dingeldey (ed.) Erwerbstätigkeit und Familie in Steuer- und Sozialversicherungssystemen. Begünstigungen und Belastungen verschiedener familialer Erwerbsmuster im Ländervergleich. Opladen: Leske + Budrich. Chapter 1, pp.11-47.

Esping-Andersen, G. (1993, 2nd reprint) The Three Worlds of Welfare Capitalism. Princeton: Princeton University Press.

Fitzenberger, B., (1999) Wages and Employment Across Skill Groups: An Analysis for West Germany. Physica-Verlag, Heidelberg.

Fitzenberger, B. and MaCurdy, T. E. (1996) Block Bootstrap Procedures for Robust Inference on Regression Estimates based on Grouped Data from Time Series of Cross-sections: Theoretical Results. Unpublished Manuscript, University of Konstanz and Stanford University.

Fitzenberger, B. and Wunderlich, G. (2000) Gender Wage Differences in West Germany: A Cohort Analysis. Discussion Paper 00-48, Centre for European Economic Research (ZEW), Mannheim.

Fitzenberger, B., R. Hujer, T.E. MaCurdy, and R. Schnabel (2001) Testing for Uniform Wage Trends in West Germany: A Cohort Analysis using Quantile Regressions for Censored Data. Empirical Economics, pp. 41-87. 
Franz, W. (1999) Arbeitsmarktökonomik. Berlin, Heidelberg, and New York: Springer.

Goldin, C. (1990) Understanding the Gender Gap. An Economic History of American Women. New York, Oxford: Oxford University Press, Chapter 5: The Changing Economic Role of Married Women. pp.119-158.

Hakim, C. (1993) The Myth of Rising Female Employment. Work, Employment and Society, Vol. 7, pp.97-120.

Jacobsen, J. P. (1998) Labor Force Participation: Analysis of Trends. In: J.P. Jacobsen, The Economics of Gender. 2nd ed., Oxford: Blackwell, Chapter 4, pp.106-153.

Killingsworth, M. and J. J. Heckman (1986) Female Labour Supply: A Survey. In: O. Ashenfelter and R. Layard (eds.) Handbook of Labour Economics, Volume I, Chapter 2.

Kommission für Zukunftsfragen der Freistaaten Bayern und Sachsen (1996) Erwerbstätigkeit und Arbeitslosigkeit in Deutschland. Entwicklung von Erwerbstaetigkeit und Arbeitslosigkeit in Deutschland und anderen frühindustrialisierten Laendern. Bonn.

OECD (1988) Employment outlook. Paris: OECD.

OECD (1997) Education at a glance. OECD Indicators. Paris: OECD. Chapter E: Social and labour market outcomes of education. pp.239-276.

Pencavel, J. (1986) Labor Supply of Men: A Survey. In: O. Ashenfelter and R. Layard (eds.) Handbook of Labour Economics, Volume I, Chapter 1.

Rubery, J., M. Smith and C. Fagan (1999) Women's Employment in Europe. Trends and Prospects. London and New York: Routledge.

Shapiro, D. and F. L. Mott (1994) Long-Term Employment and Earnings of Women in Relation to Employment Behavior Surrounding the First Birth. The Journal of Human Resources. Vol. 24, pp.249-275.

Shaw, K. (1994) The Persistence of Female Labor Supply. Journal of Human Resources, Vol. 24, pp.348-378. 


\section{A Appendix}

\section{A.1 Data}

The empirical analysis in this study is based on data from the Microcensus ("Mikrozensus", an annual population survey) for West Germany. We construct gender, skill, and age specific employment and participation rates for various years from 1976 to 1995 (see section 3).

$\begin{array}{lll}\text { We define: } & \text { EMP } & \text { number of unemployed persons, } \\ & \text { nP } & \text { number of employed persons, and } \\ & \text { non-participants. }\end{array}$

The size of an age-skill group (population) is the sum $\mathrm{POP}=\mathrm{EMP}+\mathrm{UN}+\mathrm{NP}$. The employment rate is the ratio $\mathrm{EMP} / \mathrm{POP}$, and the participation rate is given by the ratio $(\mathrm{EMP}+\mathrm{UN}) / \mathrm{POP}$.

\section{Correction for missing skill information}

In the years 1980, 1982, 1985, 1987, and 1989, the Microcensus required the respondents to provide the information about their formal education and vocational training. This data was used to infer the skill groups, based on our above mentioned definitions, of the respondents. Hence, for these years, the share of missing observations in the skill variable is fairly small (it is close to zero among the employed and the unemployed persons). However, in the years 1976, 1991, 1993, and 1995, answering the skill question was optional resulting in a high frequency of missing answers. Since the response behavior seems related to the skill level of the person and the labor market status, we develop the following correction procedure.

The correction is applied separately for the three labor market states (EMP, UN, NP). We define cells $c l$ of persons with a given age, year, sex, and labor market status. The share of persons in this cell who have provided the skill information $(\mathrm{U}, \mathrm{M}, \mathrm{H})$ in the interview is denoted by $s_{U}(c l), s_{M}(c l)$, and $s_{H}(c l)$ and the corresponding share of persons with missing skill information by $s_{m i}(c l)$.

We assume that the share of persons with missing skill information among the persons in a certain cell $s_{m i}(\mathrm{cl})$ affects the shares of persons with reported skill information $(j \in\{U, M, H\})$ in a linear way as follows

$$
s_{j}(c l)=\beta_{j, 0}-\beta_{j}^{m i} \cdot s_{m i}(c l)+\beta_{j}^{t} \cdot t+\beta_{j}^{c} \cdot c
$$

where $t$ is a linear time trend and $c$ denotes the cohort (三 year of birth of the center in the respective age group in a year). Since $s_{U}(c l)+s_{M}(c l)+s_{H}(c l)+s_{m i}(c l)=1$, it follows that $\beta_{U}^{m i}+\beta_{M}^{m i}+\beta_{H}^{m i}=1$. Provided suitable estimates $\hat{\beta}_{j}^{m i}$ are available, we argue that we could reasonably predict the true shares $\hat{s}_{j}(c l)$ of the three skill groups 
within the cell $c l$ by

$$
\hat{s}_{j}(c l)=s_{j}(c l)+\hat{\beta}_{j}^{m i} \cdot s_{m i}(c l)
$$

and thus correct the reported skill specific numbers of persons for the three labor market states by

$$
N_{j}(c l)=\hat{s}_{j}(c l) \cdot N(c l)
$$

where $N(c l)$ is the total number of persons in the cell (defined by age group, year, gender, and labor market status) and $N_{j}(\mathrm{cl})$ the number of persons in the cell with skill level $j$.

We obtain $\hat{\beta}_{j}^{m i}$ by estimating the system of equations (6) using the SURE Method. Based upon a logit transformation of the coefficients, we impose the restriction that $\hat{\beta}_{U}^{m i}+\hat{\beta}_{M}^{m i}+\hat{\beta}_{H}^{m i}=1$ and that all estimated $\hat{\beta}_{j}^{m i}$ lie within the interval $[0,1]$.

\section{A.2 Methodological Details of the Empirical Approach}

The goal of the empirical analysis is to analyze trends both in the participation rate and the employment rate by skill group and gender. Let PER denote the participation or the employment rate. We investigate movements in PER for synthetic cohorts over time. Testing for uniformity across cohorts allows to investigate whether PER moves uniformly over time. Alternatively, it could be the case that PER trends differ across cohorts, which would then indicate the presence of "cohort effects". Under certain conditions, which will be discussed later, a cohort effect designates a movement of the entire life-cycle PER profile for a given cohort relative to other cohorts. In providing a parsimonious representation, we are able to pin down precisely the differences in PER trends across groups of workers defined by gender and skill level. We also explicitly take into account the possibility that PER is sensitive to cyclical effects.

\section{A.2.1 Characterizing Profiles in Participation or Employment Rates}

We denote the age of a person by $\alpha$ and the calendar time by $t$. A cohort $c$ can be defined by the year of birth. The variables age, cohort, and calendar year are linked by the relation $t=c+\alpha$. Often researchers investigate empirically the cross-sectional relation between age and PER in a given year and trends in this relationship over time:

$$
\operatorname{PER}(t, \alpha)=f(t, \alpha)+u
$$

The deterministic function $f$ measures the systematic variation in PER, and $u$ reflects cyclical or transitory phenomena. Movements of $f$ as a function of $t$ describe how crosssection age profiles in PER shift over time. The cross-sectional relation $f$ as a function of age does not describe the "life-cycle" profile for any cohort, or, put differently, the cross-section relation may very well be the result of "cohort effects". Profiles in PER can also be expressed as a function of cohort and age

$$
g(c, \alpha) \equiv g(t-\alpha, \alpha) \equiv f(t, \alpha)
$$


where the deterministic function $g$ describes how age- $P E R$ profiles differ across cohorts. Holding age constant, $g(c, \alpha)$ describes PER for different cohorts over time. Holding the cohort constant yields the profile experienced by a specific cohort over time and age. The latter can be interpreted as the actual PER profile, because it reflects the movements of PER over the actual life-cycle for a given cohort.

The different parameterizations $g(c, \alpha)$ and $f(t, \alpha)$ are equivalent representations of the same relationship. Without further assumptions, "pure life-cycle effects" due to aging or "pure cohort effects" cannot be identified. Because of our focusing on PER trends for a given cohort over time, we use the cohort representation in equation (8) as the perspective of our analysis.

\section{A.2.2 Testing for Uniform Changes over Time}

Our analysis investigates whether time trends in PER are uniform across cohorts, in the sense, that every cohort experiences the same time trend and the same age related change. The latter is interpreted here as the life-cycle effect (三"pure age effect"). Despite the identification issues discussed above, the existence of a uniform time trend across cohorts is a testable implication in the framework presented here. If such a uniform time trend is found, it is designated as the macroeconomic trend for the group considered. ${ }^{11}$ However, as can be seen from the empirical results, the uniform time trends found differ by skill level, gender, and employment status.

Two notions of changes over time prove useful: First, changes for a given cohort in the labor market over time ("Insider trend"), and second, changes over time experienced by successive cohorts when entering the labor market ("Entry trend"). The Insider trend is given by

$$
\left.\frac{\partial g}{\partial t}\right|_{c}=\left.\frac{\partial g}{\partial \alpha}\right|_{c} \equiv g_{\alpha}(c, \alpha) \equiv g_{\alpha},
$$

resulting from the simultaneous change of time and age. Alternatively, holding age constant yields the change observed over different cohorts at a given age. For the age at labor market entry, $\alpha_{e}$, the Entry trend is given by

$$
\left.\frac{\partial g}{\partial t}\right|_{\alpha=\alpha_{e}}=\left.\frac{\partial g}{\partial c}\right|_{\alpha=\alpha_{e}} \equiv g_{c}\left(c, \alpha_{e}\right)=g_{c}\left(t-\alpha_{e}, \alpha_{e}\right) \equiv e(t)
$$

Again, this results from two effects, a change of cohort and time.

Now, two testable separability conditions arise. If the changes over time can be characterized as the sum of a pure aging effect and a pure time effect in the following way

$$
g_{\alpha}=a(\alpha)+b(t)=a(\alpha)+b(c+\alpha),
$$

\footnotetext{
${ }^{11}$ If no uniform trend is found, the average across age groups combines age, time, and cohort effects.
} 
then the life-cycle effect is independent of the calendar year $t$. This condition is designated as the "uniform Insider trend hypothesis", which we denote by $H_{U I}$. It implies that each cohort faces the same change in PER over the life-cycle due to aging $a(\alpha)$ and that economy wide shifts $b(t)$ are common to all cohorts in the same year but they occur at different points during the life-cycle of each cohort. If the separability condition (11) holds, we can construct a "life-cycle profile" independent of the calendar year and a macroeconomic time trend independent of age. Condition (11) is violated if interaction terms of $\alpha$ and $t$ enter the specification of $g_{\alpha}$.

Integrating back the derivative condition (11), with respect to $\alpha$, yields an additive form for the systematic component of the PER function $g(c, \alpha)$ :

$$
g(c, \alpha)=G+K(c)+A(\alpha)+B(c+\alpha)
$$

where $G+K(c)$ is the cohort specific constant of integration. $H_{U I}$ can be tested by investigating whether "interaction terms" $R(\alpha, t)$ enter specification (12), which are constructed as integrals of interaction terms of $\alpha$ and $t$ in $g_{\alpha}$.

If, in addition to $H_{U I}$, the Entry trend equals the macroeconomic time trend

$$
e(t)=b(t)
$$

a stronger hypothesis can be formulated. We designate this hypothesis as the "Hypothesis of uniformity in the Insider trend and the Entry trend" and denote it as $H_{U}$. Under this hypothesis the life-cycle profile of each new labor market cohort is a parallel shift of the profile of the previous cohort corresponding to the uniform time trend $b(t)$ for all cohorts already in the labor market. Again, this is a testable implication. Given specification (12), condition (13) implies that $K(c)$ is equal to zero for the cohorts entering the labor market during the period of observation.

\section{A.2.3 Implementation of the Tests}

The hypothesis $H_{U I}$ requires equation (12) to hold against a more general alternative, whereas the (stronger) hypothesis $H_{U}$ additionally requires $K_{a 2}=0$ (no cohort effect after 1976). Formally, it is also possible to test the hypothesis that $K_{b 2}=0$ and $K_{b 3}=0$. This test of equation (13) for older cohorts is not directly based on the entry age, because these cohorts are only observed in the data during a later phase of their life-cycle.

In order to formulate a test of $H_{U I}$, we consider in the derivative $g_{\alpha}$ the interaction term $\alpha t$. The implied non-separable variant of $g(c, \alpha)$ expands (12) by incorporating the integral of this interaction term

$$
R=\int \alpha(c+\alpha) d \alpha=c \alpha^{2} / 2+\alpha^{3} / 3
$$


Consequently, the most general formulation of equation (12) also involves $R$ and the orthogonalized year dummies. The formal test of $H_{U I}$ is a test in order to indicate whether or not $R$ is significant. The test of the stronger hypothesis $H_{U}$ is a test of whether or not both $R$ and $c a^{2}$ are significant.

Only if the separability condition $H_{U I}$ holds, is it meaningful to construct an index of a life-cycle profile, as a function of pure aging $A(\alpha)$, and a linear macroeconomic trend index $B(t)$. Otherwise, a different PER profile would apply for each cohort. As pointed out above, it is important to recognize that neither the level nor the coefficient on the linear term are identified for these indices in a strict econometric sense.

\section{A.2.4 Block Bootstrap Procedure for Inference}

In the context of this study, we allow for the error terms being dependent across individuals within cohort-year-cells and across adjacent cohort-year-cells. The dependence is assumed to take the form of rectangular $\mathrm{m}$-dependence across time and across cohorts. We use a flexible Block Bootstrap approach allowing for standard error estimates, which are robust against fairly arbitrary heteroskedasticity and autocorrelation of the error term (see Fitzenberger and MaCurdy (1996) for a theoretical analysis of this method, as well as Fitzenberger (1999), and Fitzenberger and Wunderlich (2000), and Fitzenberger et al. (2001) for applications in the context of estimating wage equations). The Block Bootstrap approach employed here extends the standard bootstrap procedure in that it draws blocks of observations to form the resamples. For each observation in a block, the entire vector comprising the endogenous variable and the regressors is used, i.e. we do not draw from the estimated residuals. We draw a two-dimensional block of observations with a block length of 10 in the cohort and 10 in the time dimension with replacement until the resample has become at least as large as the resample size. Accordingly, standard error estimation takes account of error correlation both within a cohort-year-cell and across pairs of cohorts and time periods which are at most 9 years in the cohort dimension and 9 years in the time dimension apart. In the absence of a clear cut decision rule about the choice of blocksize, we experimented somewhat with slightly smaller and larger blocks without causing changes in the substance of the results. 


\section{A.3 Figures and Tables}

Figure 1: Relative size of skill groups by age from 1976-1995
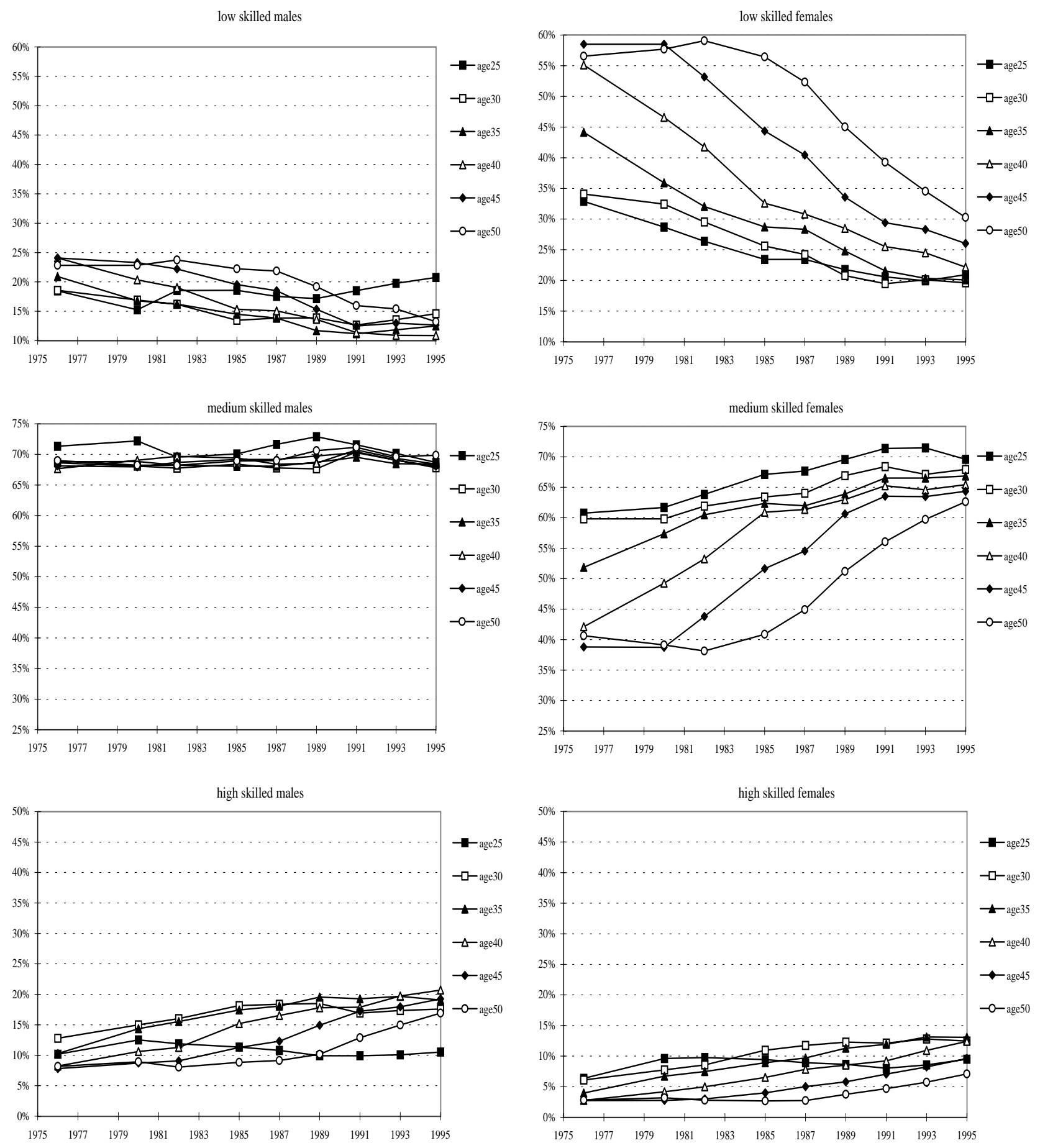
Figure 2: Employment Rates of skill groups by age from 1976-1995
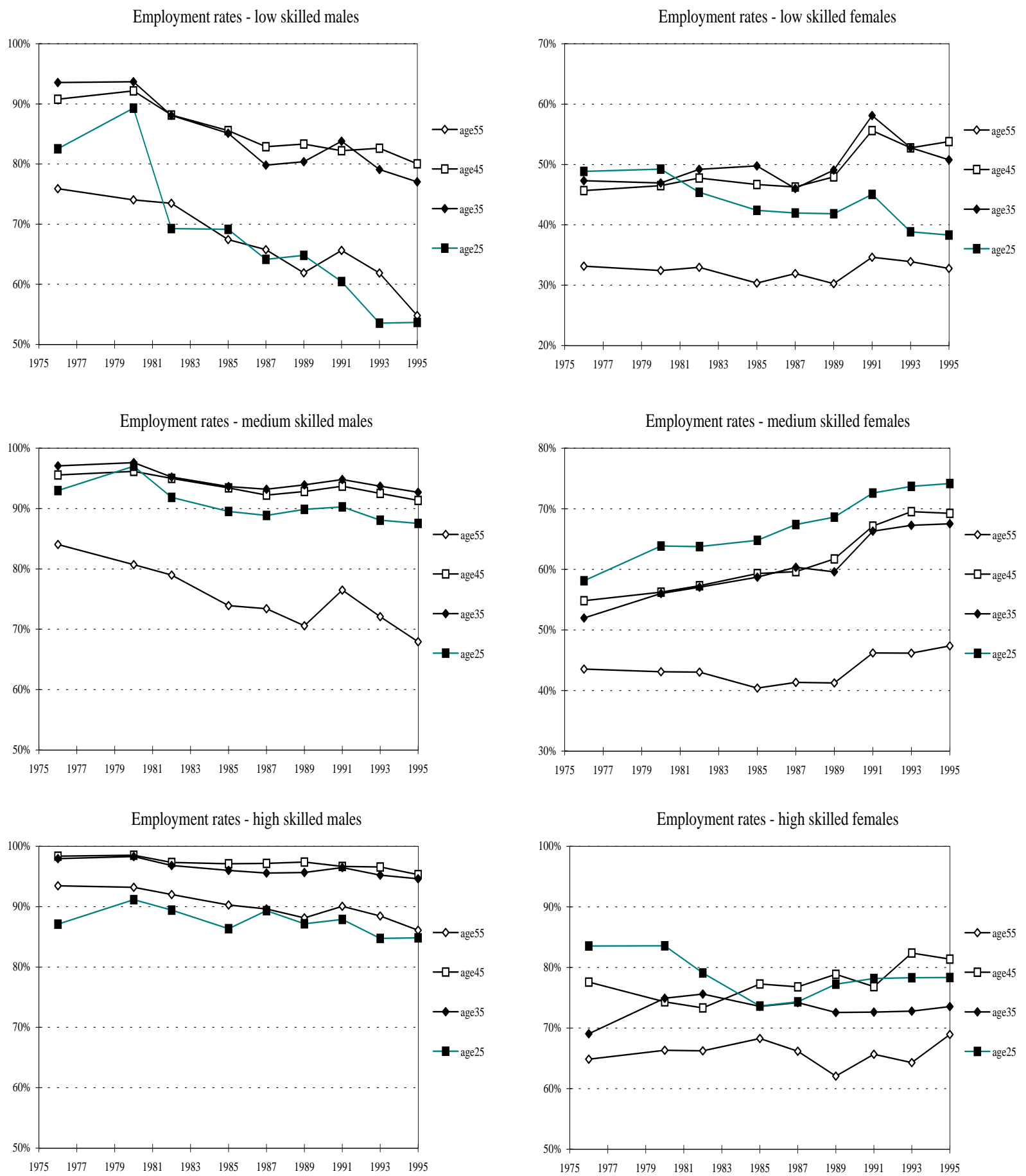
Table 1: Parameter Estimates of Participation Rates for Males and Females for Skill Groups U (Low Skilled), M (Medium Skilled), and H (High Skilled).

\begin{tabular}{|c|ccc|ccc|}
\hline Groups & \multicolumn{3}{|c|}{ Females } & \multicolumn{3}{c|}{ Males } \\
\hline Skill Level & $U$ & $M$ & $H$ & $U$ & $M$ & $H$ \\
\hline \hline Specification & $(2)$ & $(3)$ & $(4)$ & $(1)$ & $(1)$ & $(1)$ \\
\hline Intercept & 0,490 & 0,667 & 0,884 & 0,670 & 0,921 & 0,918 \\
& $(0,010)$ & $(0,012)$ & $(0,007)$ & $(0,030)$ & $(0,006)$ & $(0,006)$ \\
\hline$t 1$ & 0,074 & 0,094 & - & $-0,038$ & $-0,007$ & $-0,005$ \\
& $(0,011)$ & $(0,006)$ & - & $(0,012)$ & $(0,002)$ & $(0,002)$ \\
\hline$a 1$ & $-0,082$ & $-0,338$ & $-0,260$ & 0,369 & 0,098 & 0,092 \\
& $(0,026)$ & $(0,028)$ & $(0,027)$ & $(0,041)$ & $(0,008)$ & $(0,008)$ \\
\hline$a 2$ & 0,090 & 0,266 & 0,203 & $-0,103$ & $-0,033$ & $-0,026$ \\
& $(0,019)$ & $(0,024)$ & $(0,024)$ & $(0,013)$ & $(0,002)$ & $(0,003)$ \\
\hline$a 3$ & $-0,026$ & $-0,060$ & $-0,041$ & - & - & - \\
& $(0,004)$ & $(0,005)$ & $(0,006)$ & - & - & - \\
\hline$c b 2$ & $-0,020$ & $-0,039$ & $-0,081$ & - & - & - \\
& $(0,012)$ & $(0,011)$ & $(0,017)$ & - & - & - \\
\hline$c b 3$ & $-0,009$ & $-0,015$ & $-0,022$ & - & - & - \\
& $(0,004)$ & $(0,004)$ & $(0,008)$ & - & - & - \\
\hline$c a 2$ & $-0,056$ & - & - & - & - & - \\
& $(0,018)$ & - & - & - & - & - \\
\hline
\end{tabular}

Remark: The estimate of the covariance matrix is obtained using a Block Bootstrap Procedure (1000 resamples for skill groups (U) and (M) and (H)). Participation rates are defined as $p r=(e m p+u n p) / p o p$. Standard errors are found in parantheses. 
Table 2: Parameter Estimates of Employment Rates for Males and Females for Skill Groups U (Low Skilled), M (Medium Skilled), and H (High Skilled).

\begin{tabular}{|c|ccc|ccc|}
\hline Groups & \multicolumn{3}{|c|}{ Females } & \multicolumn{3}{c|}{ Males } \\
\hline Skill Level & $U$ & $M$ & $H$ & $U$ & $M$ & $H$ \\
\hline \hline Specification & $(2)$ & $(3)$ & $(4)$ & $(1)$ & $(1)$ & $(1)$ \\
\hline Intercept & 0,437 & 0,633 & 0,817 & 0,623 & 0,893 & 0,875 \\
& $(0,017)$ & $(0,012)$ & $(0,015)$ & $(0,028)$ & $(0,006)$ & $(0,006)$ \\
\hline$t 1$ & 0,028 & 0,078 & - & $-0,087$ & $-0,023$ & $-0,015$ \\
& $(0,013)$ & $(0,006)$ & - & $(0,011)$ & $(0,002)$ & $(0,003)$ \\
\hline$a 1$ & $-0,031$ & $-0,334$ & $-0,250$ & 0,360 & 0,106 & 0,126 \\
& $(0,035)$ & $(0,030)$ & $(0,042)$ & $(0,033)$ & $(0,007)$ & $(0,008)$ \\
\hline$a 2$ & 0,077 & 0,270 & 0,213 & $-0,097$ & $-0,035$ & $-0,033$ \\
& $(0,023)$ & $(0,025)$ & $(0,032)$ & $(0,011)$ & $(0,002)$ & $(0,003)$ \\
\hline$a 3$ & $-0,024$ & $-0,062$ & $-0,045$ & - & - & - \\
& $(0,005)$ & $(0,006)$ & $(0,007)$ & - & - & - \\
\hline$c b 2$ & $-0,030$ & $-0,031$ & $-0,050$ & - & - & - \\
& $(0,015)$ & $(0,010)$ & $(0,015)$ & - & - & - \\
\hline$c b 3$ & $-0,010$ & $-0,013$ & $-0,013$ & - & - & - \\
& $(0,005)$ & $(0,004)$ & $(0,006)$ & - & - & - \\
\hline$c a 2$ & $-0,039$ & - & - & - & - & - \\
& $(0,021)$ & - & - & - & - & - \\
\hline
\end{tabular}

Remark: The estimate of the covariance matrix is obtained using a Block Bootstrap Procedure (1000 resamples for skill groups (U) and (M) and (H)). Employment rates are defined as $e r=e m p / p o p$. Standard errors are found in parantheses. 
Figure 3: Participation Rates - Time Trends, Age and Cohort Profiles for Males and Females for Skill Groups U (Low Skilled), M (Medium Skilled), and H (High Skilled). Based on Preferred Final Specifications.

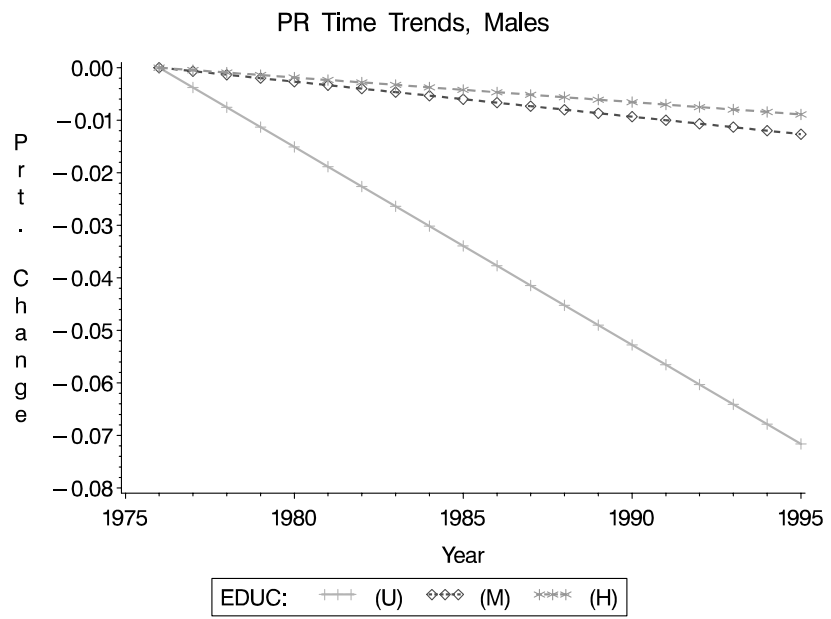

PR Age Profiles, Males

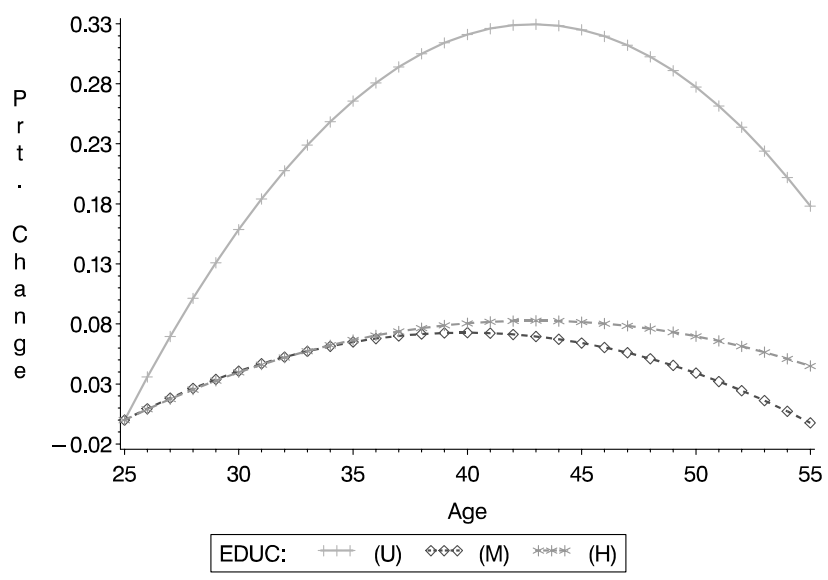

PR Time Trends, Females

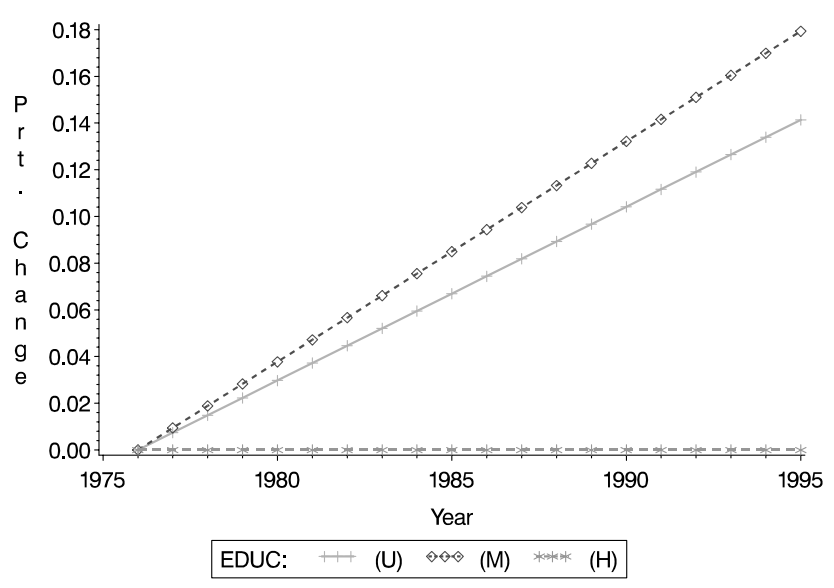

PR Age Profiles, Females

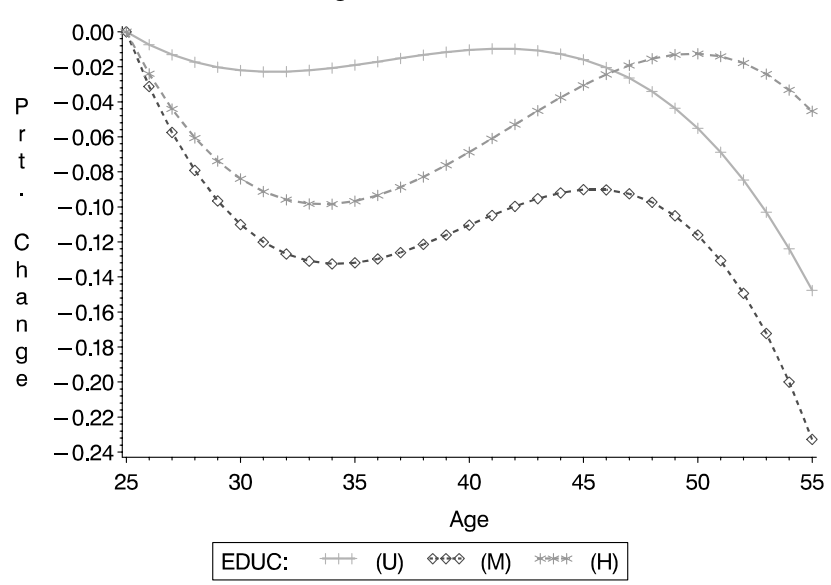

PR Cohort Profiles, Females

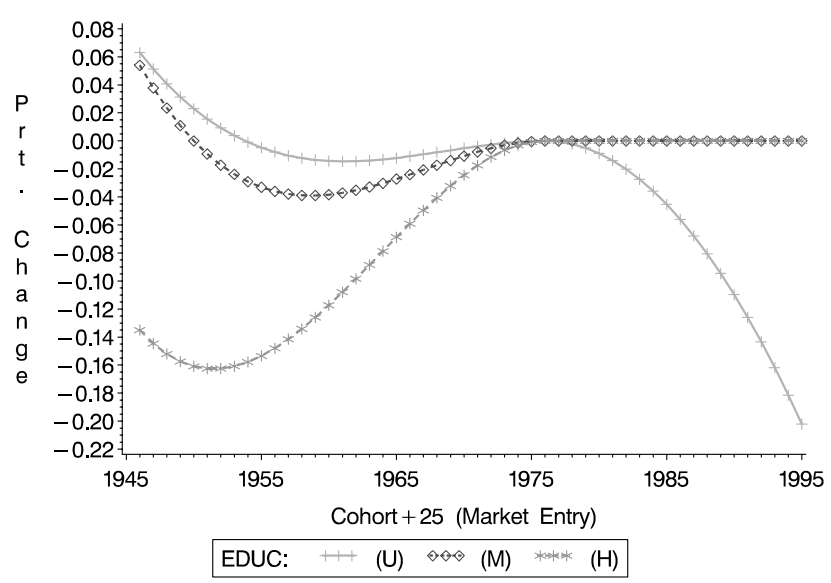


Figure 4: Cross-sections of Predicted Participation Rates 1985 and Cohort Profiles of Males and Females for Skill Groups U (Low Skilled), M (Medium Skilled), and H (High Skilled). Based on Preferred Final Specifications.

Cross - section and Cohort Profiles in Participation Males, Low - skilled

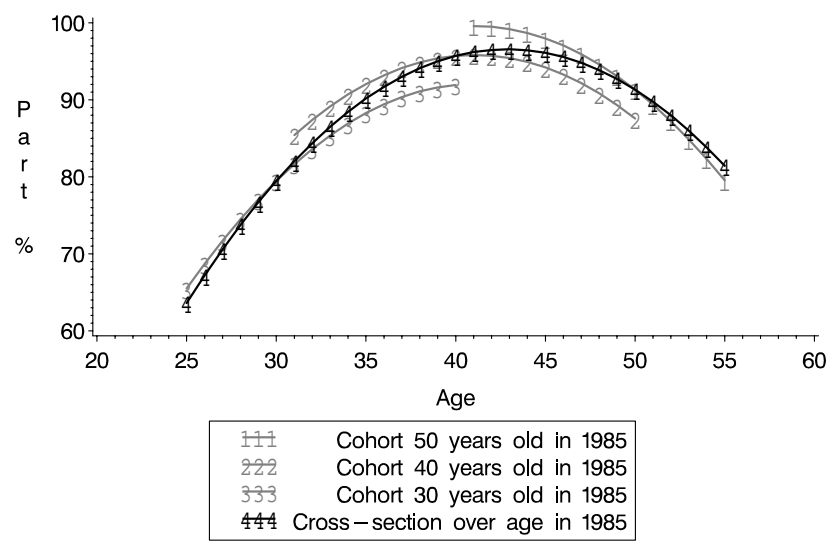

Cross - section and Cohort Profiles in Participation Males, Medium - skilled

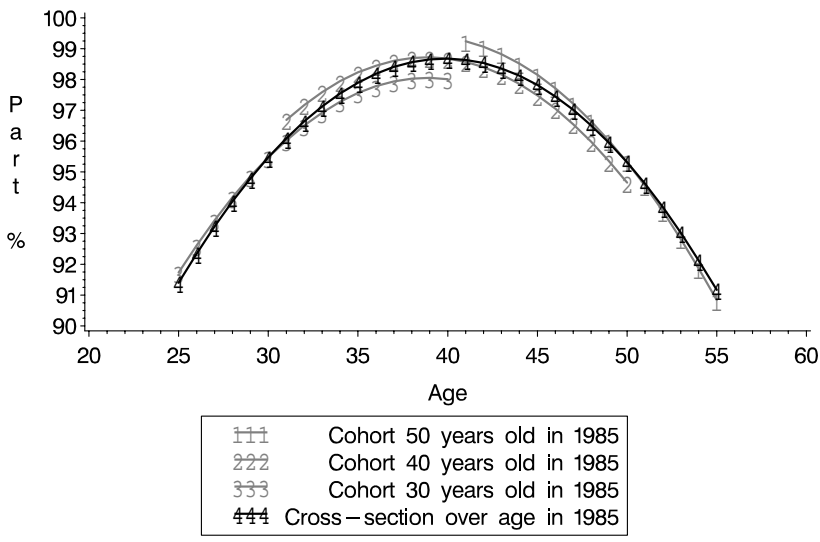

Cross - section and Cohort Profiles in Participation Males, High-skilled

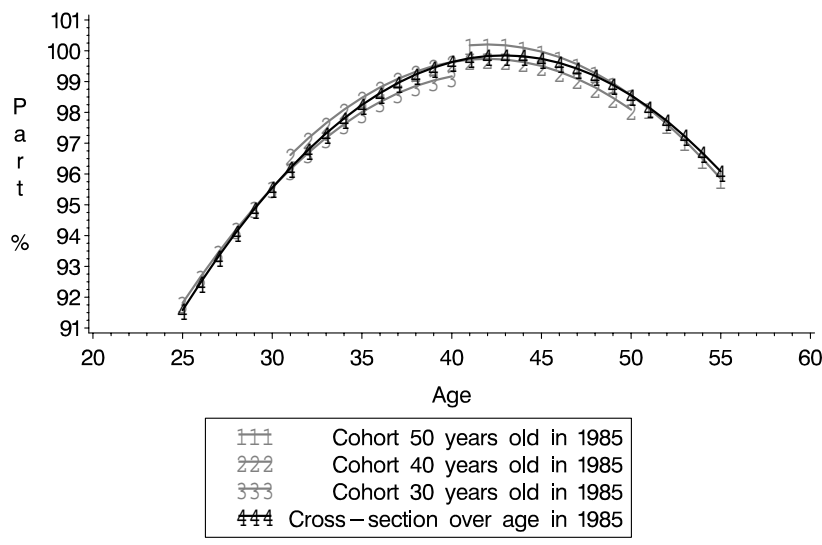

Cross - section and Cohort Profiles in Participation Females, Low - skilled

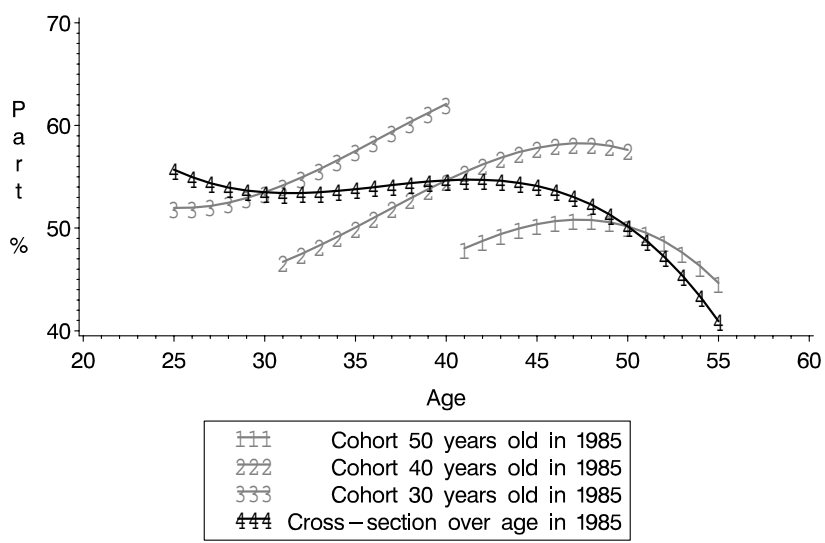

Cross - section and Cohort Profiles in Participation Females, medium - skilled

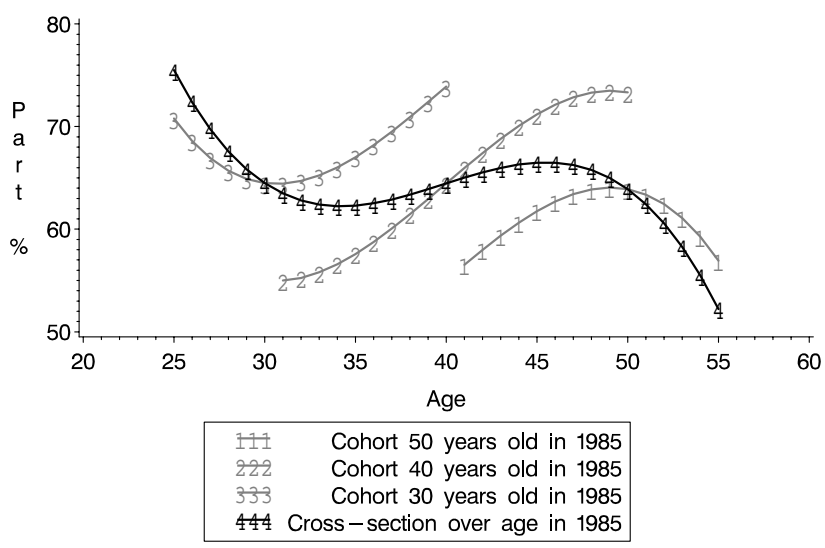

Cross - section and Cohort Profiles in Participation Females, high-skilled

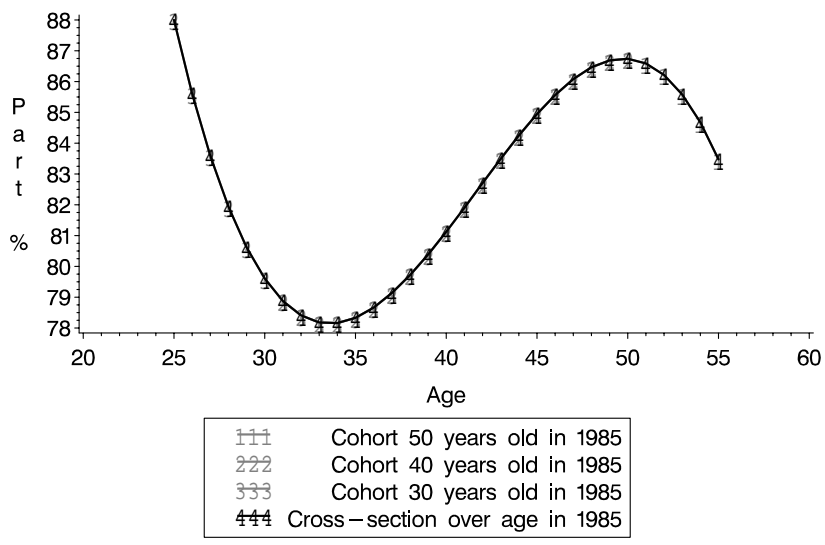


Figure 5: Employment Rates - Time Trends, Age and Cohort Profiles for Males and Females for Skill Groups U (Low Skilled), M (Medium Skilled), and H (High Skilled). Based on Preferred Final Specifications.

ER Time Trends, Males

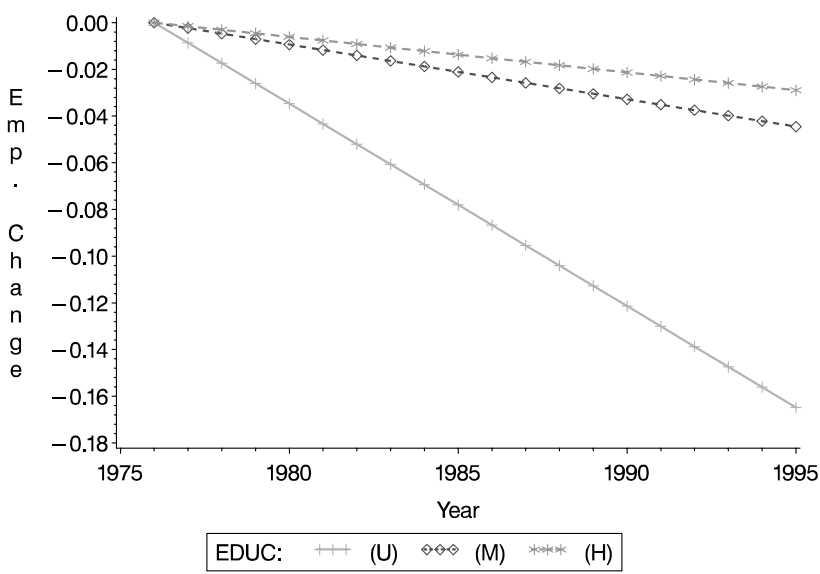

ER Age Profiles, Males

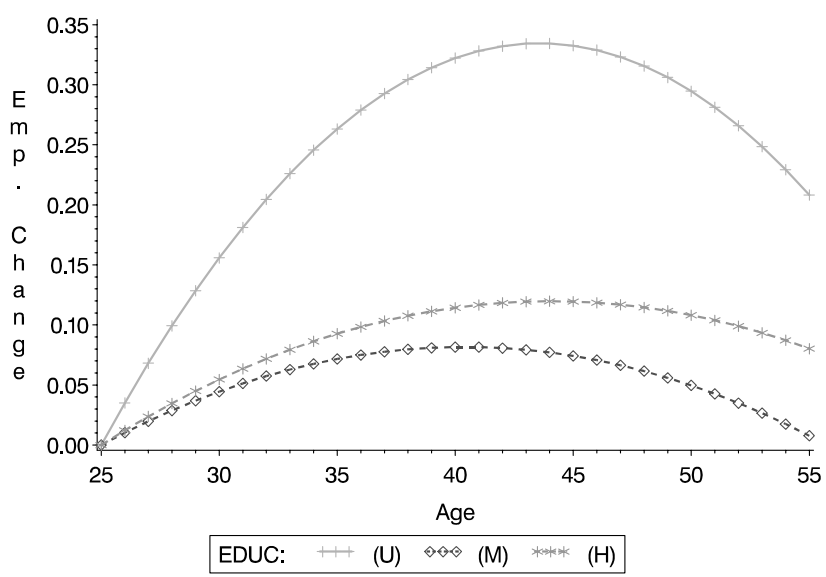

ER Time Trends, Females

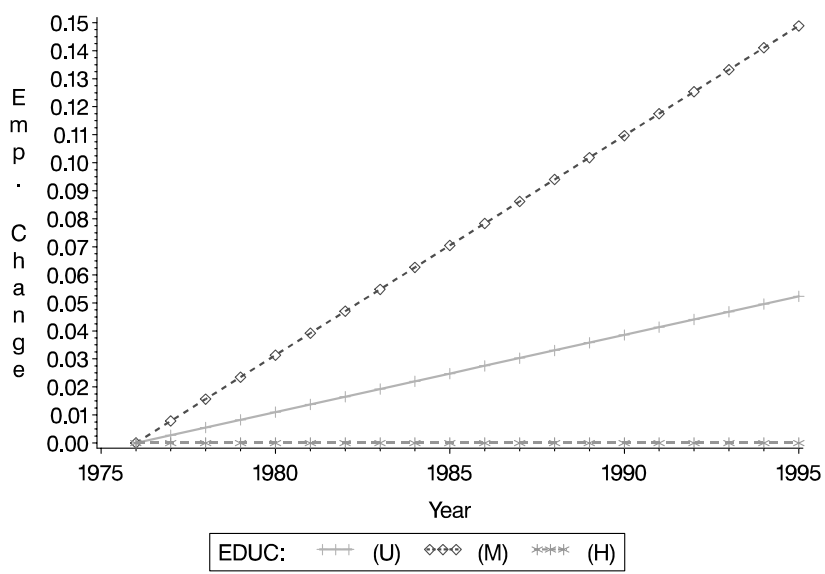

ER Age Profiles, Females

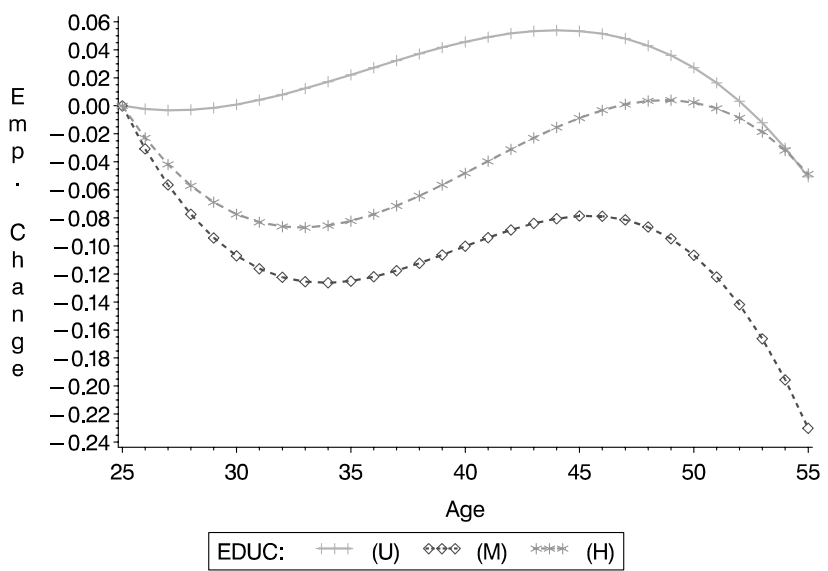

ER Cohort Profiles, Females

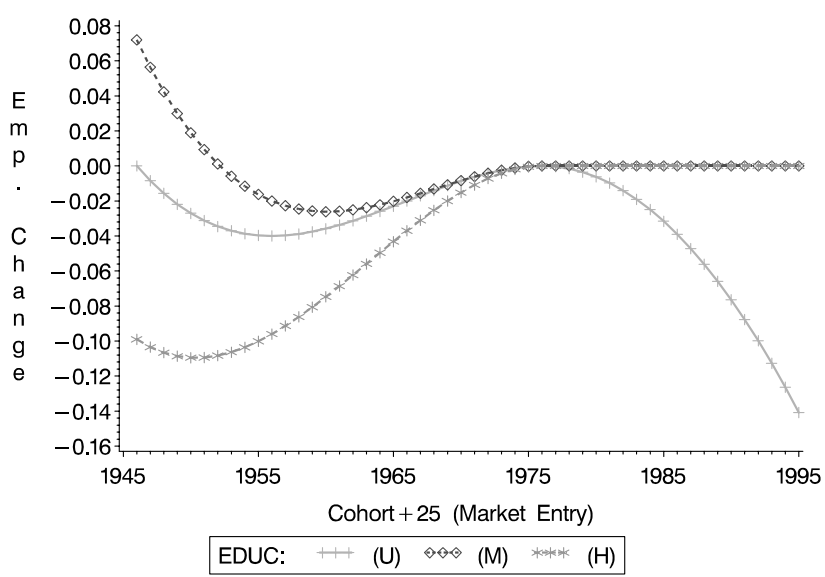


Figure 6: Cross-sections of Predicted Employment Rates 1985 and Cohort Profiles of Males and Females for Skill Groups U (Low Skilled), M (Medium Skilled), and H (High Skilled). Based on Preferred Final Specifications.

Cross - section and Cohort Profiles in Employment Males, Low - skilled

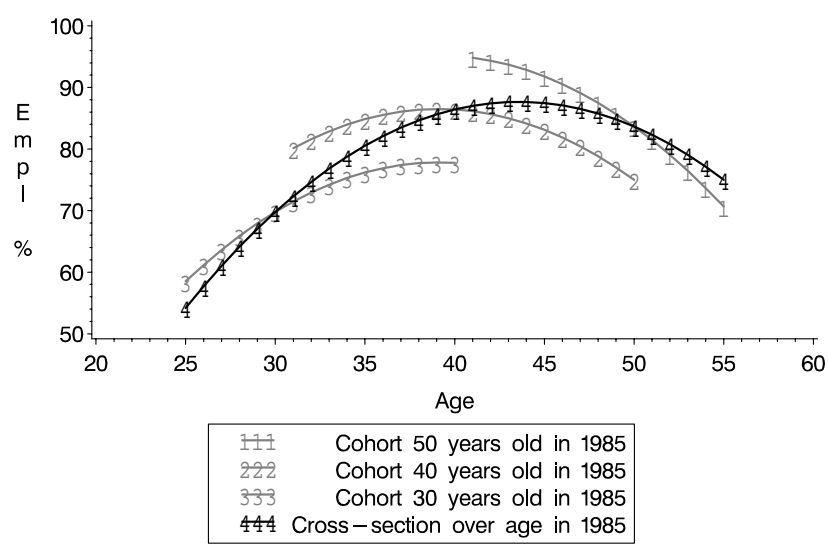

Cross - section and Cohort Profiles in Employment Males, Medium - skilled

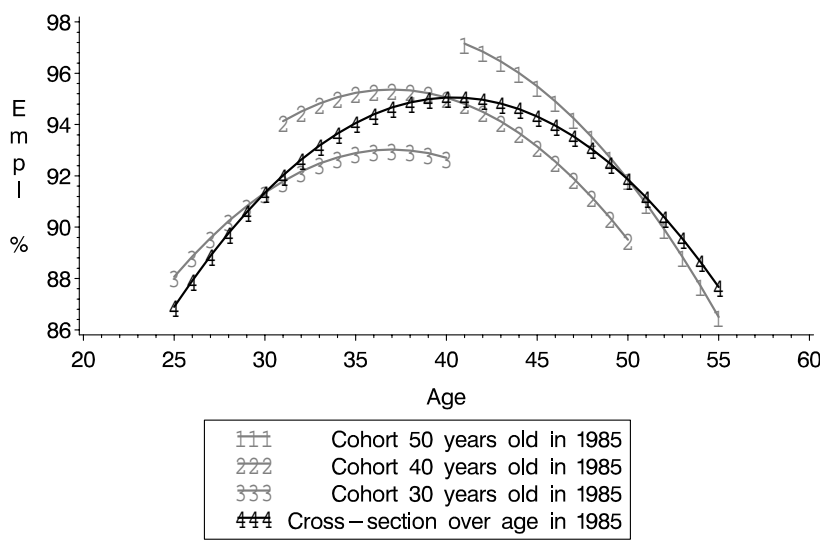

Cross - section and Cohort Profiles in Employment Males, High - skilled

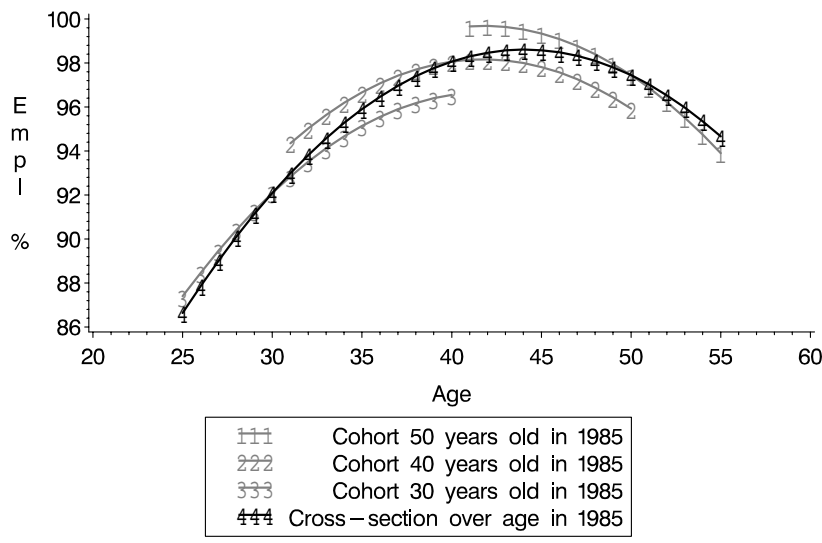

Cross - section and Cohort Profiles in Employment Females, Low-skilled

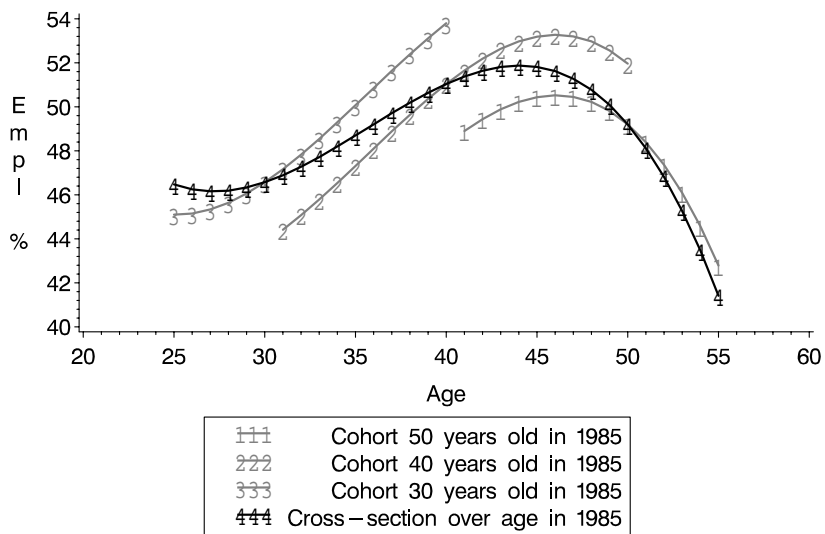

Cross - section and Cohort Profiles in Employment Females, medium - skilled

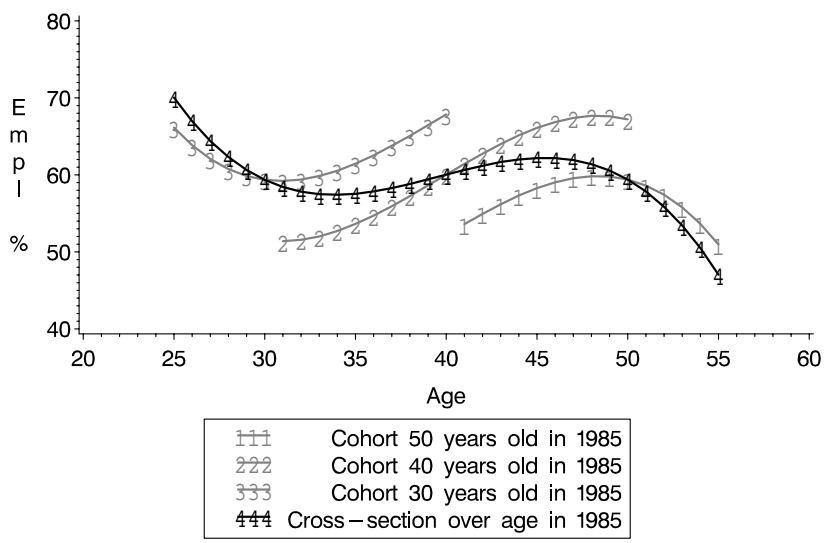

Cross - section and Cohort Profiles in Employment Females, high-skilled

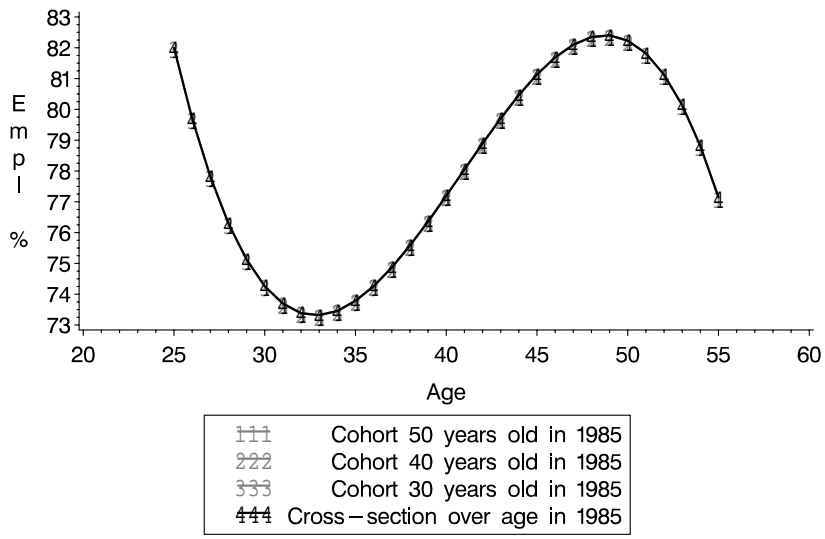

